Boise State University

ScholarWorks

$10-2014$

\title{
Luminescence Dating Without Sand Lenses: an Application of OsI to Coarse-grained Alluvial Fan Deposits of the Lost River Range, Idaho, USA
}

\author{
M. K. Kenworthy \\ Boise State University \\ T. M. Rittenour \\ Utah State University \\ J. L. Pierce \\ Boise State University \\ N. A. Sutfin \\ Boise State University \\ W. D. Sharp \\ Berkeley Geochronology Center
}

NOTICE: this is the author's version of a work that was accepted for publication in Quaternary Geochronology. Changes resulting from the publishing process, such as peer review, editing, corrections, structural formatting, and other quality control mechanisms may not be reflected in this document. Changes may have been made to this work since it was submitted for publication. A definitive version was subsequently published in Quaternary Geochronology, 23 (2014). DOI: 10.1016/j.quageo.2014.03.004 


\section{Luminescense Dating Without Sand Lenses: An Application of OSL to Coarse-Grained Alluvial Fan Deposits of the Lost River Range, Idaho, USA}

\author{
M.K. Kenworthy* \\ Department of Geosciences \\ Boise State University \\ Boise, Idaho \\ kenw3427@vandals.uidaho.edu \\ T.M. Rittenour \\ Department of Geology \\ Utah State University \\ Logan, UT \\ J.L. Pierce \\ Department of Geosciences \\ Boise State University \\ Boise, Idaho \\ jenpierce@boisestate.edu
}

\author{
N.A. Sutfin \\ Department of Geosciences \\ Boise State University \\ Boise, Idaho \\ W.D. Sharp \\ Berkeley Geochronology Center \\ Berkeley, CA
}

\section{Introduction}

Fluvial and alluvial deposits contain important archives of past climate and tectonic events, yet commonly lack organic material for radiocarbon dating, and as such are increasingly dated by optically stimulated luminescence (OSL) techniques. OSL dating can have advantages over other Quaternary dating techniques because (1) it uses sand and silt-sized quartz and feldspar grains, which are common in fluvial deposits, (2) it has a dating range of up to 100-300 ka (Murray and Olley, 2002; Rittenour, 2008), greatly surpassing the 40 ka limit of radiocarbon dating, and (3) it provides a direct estimate of the timing of deposition, rather than a minimum age as provided by cosmogenic surface exposure dating or uranium-series dating of pedogeneic carbonates (e.g. Gosse and Phillips, 2001; Sharp et al., 2003). Recent advances in the application of OSL to fluvial deposits (e.g. Wallinga, 2002; Jain et al., 2004; Rittenour, 2008) as well as general methodological advances (e.g. Murray and Wintle, 2000; Duller, 2004, 2008) have improved the accuracy and precision of resulting ages.

Incomplete solar resetting of the OSL signal prior to deposition, termed partial bleaching, is a common problem for fluvial deposits because exposure to sunlight can be reduced by the depth and turbidity of the water column. Numerous methods have been developed to detect and correct for partial bleaching, including analysis of coarser grain sizes thought to be better bleached (zeroed) during transport (e.g. Olley et al., 1998; Truelsen and Wallinga, 2003), singlegrain dating (e.g. Duller, 2008) and statistical treatment of De distributions to exclude portions representing poorly bleached and non-reset grains (e.g. Galbraith et al., 1999).

Another challenge is the application of OSL dating to gravelly fluvial deposits that lack sand lenses. For example, obtaining age control for depositional sequences within alluvial fans and river terraces can provide valuable insight into climatic and tectonic processes, but often these coarsegrained, clast supported deposits do not favor sand lens preservation. Even without sand lenses the matrix between the coarser clasts often contains sufficient sand-sized quartz or feldspar grains suitable for OSL dating. However, obtaining samples and estimating dose rate for deposits with a wide range of grain sizes and lithologies can present challenges. Advancements that overcome these difficulties are important because coarse-grained deposits are common in many diverse geomorphic settings.

Correctly accounting for dose-rate heterogeneity in coarse-grained deposits can be difficult. One approach is the use of in situ gamma spectrometry. However, correct placement of the spectrometer and interpreting the results can be complicated by poor deposit cohesiveness and lack of a clear location for measuring dose rate like the hole created when using sample tubes. The use of dosimeters may also not be feasible due to an inability to return and collect them, 
limitations on maximum placement time, and difficulty interpreting results for samples that were excavated over a larger area than a traditional sample collected in a sample tube. Methods which employ laboratory analysis of the sediment surrounding the OSL sample have similar problems with collecting and analyzing representative samples from pebble to cobble gravels. Regardless of how dose-rate is measured, these techniques cannot detect grain-to-grain variability in microdosimetry that can occur in settings with heterogeneous grain sizes and mineralogies.

Sediment for equivalent dose (De) estimate is most often collected by pounding a metal tube into a sand lens then removing it to retain an intact core of light-protected material. If the deposit is too compacted or cemented for a metal tube, it may be possible to remove a block of cohesive sediment and use the inner, light-protected sediment for De estimation. For dose-rate calculation a sample is collected from sediment within a $\sim 30 \mathrm{~cm}$ radius around the sample tube or block. Ideally, samples are collected from sand lenses $>60 \mathrm{~cm}$ thick and wide where it is reasonable to assume a homogenous beta dose-rate environment. Coarse-grained fluvial environments often lack thick sand lenses, if present at all, and are often not cohesive enough to allow removal of a block of sediment. In these cases, a modified sampling strategy is required, such as collection of bulk sediment samples at night or under light-proof tarps (e.g. Rizza et al., 2011).

The large alluvial fans of the Lost River Range (LRR) in east-central Idaho, USA are predominantly composed of gravelly sheetflood deposits that lack sand lenses. The ages of deposits such as these are of interest in the geomorphic community because they can provide insight into drivers of hillslope sediment production and geomorphic response. This paper describes the application of OSL dating to the coarse-grained deposits of LRR alluvial fans and discusses the influence of different grain-size fractions on dose-rate estimates. OSL age estimates are also compared with results from U-series dating of pedogenic carbonates from the same fan surfaces. The primary goal of this study is to determine the appropriate methods for collecting and analyzing OSL samples from fluvial or alluvial deposits with mixed grain sizes. In particular, we (1) investigate heterogeneity in the dose-rate contribution of different grain-size fractions, (2) examine potential sources of skewness, kurtosis, or overdispersion in equivalent dose distributions for samples from coarse-grained deposits, (3) compare resulting OSL ages for timing of sediment deposition with Useries ages for timing of surface stabilization, and (4) assess the reliability of age estimates using independent ages and stratigraphic relationships.

\section{Regional Setting}

The LRR lies within the northeastern extent of the Basin and Range Province of the western USA in east-central Idaho (Fig. 1). Relief of the LRR has resulted from movement along the Lost River Fault, a west-dipping normal fault that bounds the western flank of the mountain range. Bedrock is primarily Precambrian and Paleozoic limestones and quartzarenites (Haller and Crone, 2004; Skipp and Hait, 1977).

\section{Insert Figure 1 here.}

The western front of the LRR is characterized by numerous low-gradient $\left(\sim 2-4^{\circ}\right)$, largeradius $(\sim 2-6 \mathrm{~km})$ alluvial fans (Fig. 2). Under modern conditions fans are largely inactive because contributing basins produce only low-volume, intermittent discharges. This drives minor incision of fan surfaces or deposition at fan heads by small debris flows (Patterson, 2006). Thus, the ages of these fans are of interest because past climatic conditions promoted significant removal of material from contributing basins and deposition on the alluvial fans.

\section{Insert Figure 2 here.}

Surface morphology and stratigraphy suggest that the fans have developed in a stacked rather than telescoping nature. Underlying deposit characteristics suggest fluvial transport and sorting from sheetfloods have been the dominant transport processes (Pierce and Scott, 1982; Patterson, 2006). This has produced deposits composed of clast-supported gravels with planar to sub-horizontal bedding and low percentages of silt and clay (Funk, 1976; Pierce and Scott, 1982; Pierce and Colman, 1986; Patterson, 2006). Alternating coarse to fine couplets characteristic of sheetfloods (Blair and McPherson, 1994) are common. Sand lenses $>20 \mathrm{~cm}$ in thickness are rare within the broad deposits that represent the main episodes of aggradation on LRR fans and are most often found within the less extensive, younger inset deposits. 
This is an author-produced, peer-reviewed version of this article. The final, definitive version of this document can be found online at Quaternary Geochronology, published by Elsevier. Copyright restrictions may apply. doi: 10.1016/j.quageo.2014.03.004

Loess deposits cap most fan surfaces and are generally thicker $(>1 \mathrm{~m})$ on older surfaces and on fans in the southern portion of the basin. Pedogenic processes within the loess and upper fan gravels have produced weakly developed soils (Bw and Bt horizons) with the exception of significant pedogenic carbonate accumulation (stage I-III+; Giles et al., 1966; Machette, 1985; Birkeland et al., 1991) on Pleistocene-age surfaces at depths of approximately 0.15-1.15 $\mathrm{m}$.

Previous ages for LRR fans provide estimates for the timing of surface stabilization and abandonment, rather than deposition, and have large uncertainties. Pierce and Scott (1982) hypothesized that significant aggradation of LRR fans occurred during the latest Pleistocene or Pinedale glaciation (Late Wisconsin, OIS 2) based on the thickness of pedogenic carbonate pendants (coats) developed on the undersides of clasts within Bk horizons of soils and the relative positions of fan surfaces to glacial deposits. Limited U-series dating of pedogenic carbonate coats produced minimum ages for surface abandonment of $\sim 160, \sim 30$, and $\sim 23$ ka in the southern portion of the LRR (Scott et al., 1985; Pierce, 1985). Patterson (2006) obtained similar ages ( 10-60 ka) for major fan surfaces throughout the LRR basin using the pedogenic carbonate growth-rate estimates developed by Pierce (1985).

\section{OSL Methods}

\subsection{Sample collection and preparation}

Five large, low-gradient alluvial fans on the western side of the LRR were selected for study (Fig. 1). Major geomorphic depositional surfaces on each fan were mapped $\left(\mathrm{Qaf}_{1}-\mathrm{Qaf}_{4}\right)$ and targeted for optical dating (Fig. 2). Underlying alluvial fills were similarly named $\left(\mathrm{Qaf}_{1}-\mathrm{Qaf}_{4}\right)$ based on their association with periods of aggradation, largely based on their position under geomorphic fan surfaces, although this is not the case everywhere (see section 6.4). Where it was possible, samples were collected from natural exposures and abandoned gravel pits ( $\mathrm{n}=16)$. Samples were also collected from trenches dug in locations that ensured sampling of all major fan-surface deposits $(\mathrm{n}=18)$.

Of the 34 samples collected, only four were collected from sand lenses $>60 \mathrm{~cm}$ in thickness by the traditional technique of pounding an opaque metal tube into the sediment. Moreover, two of these four were collected from terraces of the East Fork Big Lost River rather than the alluvial fans. Two other samples were collected using traditional techniques involving pounding a tube into thin sand lenses ( $<20 \mathrm{~cm}$ thick). Three samples were collected from thin sand lenses $(<20 \mathrm{~cm})$ that were too discontinuous and friable for sampling with a tube. These samples were collected at night with the aid of red headlamps by first removing the outer 3-4 cm of light-exposed sediment then excavating the remaining sand into a light-safe container.

The remaining 25 samples were collected from coarse-grained sheetflood gravels that lacked sand lenses but contained sand and silt within the matrix between pebble and cobble clasts. Sandier portions of sheetflood deposits were targeted and samples were collected either underlight-safe tarps or at night to protect the sediment from light exposure. Red headlamps provided ambient light and aided sample collection but were never shone directly on the sampled sediment. The outer $\sim 3-5 \mathrm{~cm}$ of light-exposed sediment was removed prior to sampling. Loose material was also removed from a large area above the sample horizon to prevent contamination by light-exposed grains falling from above. Sediment for dating was then excavated from the deposit with a small trowel, sieved to keep light-shielded sample volume down, and the $<2 \mathrm{~mm}$ portion retained in light-safe containers. The sample area was kept as small as possible to minimize mixing deposits with different age or dose rate. Sample areas were on average approximately $30 \mathrm{~cm}$ wide, $15 \mathrm{~cm}$ high, and $15 \mathrm{~cm}$ deep but the size and shape varied as dictated by the geometry of beds with high sand content and the location of large, immobile clasts.

All sediments were sent to the Utah State University Luminescence Laboratory in Logan, Utah, USA for preparation and analysis under amber safelights. Sample preparation included wet-sieving to isolate the quartz-bearing $75-150 \mu \mathrm{m}$ grain-size fraction, treatment with hydrochloric acid and heavy liquid separation $\left(2.7 \mathrm{~g} / \mathrm{cm}^{3}\right)$. Samples were then submitted to three 30-minute treatments in concentrated hydrofluoric acid followed by a wash in concentrated hydrochloric acid. A final dry-sieve removed partially dissolved feldspars and quartz grains $<63 \mu \mathrm{m}$. The purity of the quartz sand was checked for each aliquot and aliquots containing feldspar, as indicated by a luminescence response to infrared stimulation (IRSL signal $>2$ times background), were not included in age calculations. 
This is an author-produced, peer-reviewed version of this article. The final, definitive version of this document can be found online at Quaternary Geochronology, published by Elsevier. Copyright restrictions may apply. doi: 10.1016/j.quageo.2014.03.004

\subsection{Dose-rate sampling and measurement}

When sampling thick (>60 cm) sand lenses, sediment for the dose rate estimate was collected from an approximately $30 \mathrm{~cm}$ diameter around the sample tube $(\mathrm{n}=4)$. Representative samples from this sediment were obtained from homogenized splits and U, Th, K, and Rb concentrations of pulverized sediment were measured by ICP-MS and ICPAES at ALS Chemex Labs, Elko, NV, USA.

For coarse-grained sheetflood deposits, the dose-rate samples were collected from the excavated area. All grain sizes were retained with the exception of a few large clasts that could not be removed. However, in a few samples collected during the first year of the three-year project $(n=11)$, the bulk sediment surrounding the sample horizon was not retained and the dose rate was analyzed from the sand-sized fraction $(<2 \mathrm{~mm})$ collected for OSL dating. Initially, bulk samples were not collected due to practical constrains related to the remote nature of the field sites and the difficulty of removing large boulders and cobbles. Part of the focus of this paper is to determine the influence of the grain size on dose rate and the accuracy of the age estimates from these samples in comparison to other samples collected as part of this study.

The dose-rate contribution of different grain-size fractions was investigated by analyzing the concentration of radiogenic nuclides in four different grain-size fractions; the $<2 \mathrm{~mm}$ fraction and $0.15-2.0 \mathrm{~mm}$ fraction (in sum referred to as the sand fraction), 1-5 cm fraction (pebbles) and all grain sizes present at the sample site in their correct proportions (referred to as a bulk sample). ICP-MS and ICP-AES were used to measure U, Th, K, and Rb concentrations of homogenized bulk samples following crushing. Concentrations of U, Th, and K in the bulk samples were also determined by geranium semiconductor gamma spectrometry and K concentrations analyzed with XRF at the USGS Luminescence Dating Laboratory in Denver, Colorado. Concentrations obtained with gamma spectrometry are based on at least eight separate measurements per sample with samples shaken between each measurement to account for the potential influence of the geometric arrangement of the sediment. Error calculations for elemental concentrations include standard deviation on repeat analyses and follow Goble et al. (2004) with errors assumed to approach $100 \%$ as lower ICP-MS detection limits are approached for each element. An additional 25\% uncertainty was added to dose-rate calculations from samples where bulk sediment samples were not available (see section 5.3 for discussion). Moisture content used to calculate dose rate was based on the measured in situ water content and modeled to include wetter conditions during the late Pleistocene. Moisture content of the deposits was assumed to be $3 \pm 3 \%$ during the Holocene (or in situ values if $>3 \%$ ), and $8 \pm 8 \%$ during the late Pleistocene, with $10 \mathrm{ka}$ used as the boundary between the two time periods. For samples of late-Pleistocene age, the dose rate was calculated by multiplying the dose rate calculated for Holocene water content and the dose rate calculate for late Pleistocene water content by the fraction of time the sample is assumed to have experienced each condition. As age is affected by using different moisture contents, the final dose rate was calculated in an iterative fashion. Total dose rates were calculated based on cosmic contribution, concentration of radiogenic nuclides, and moisture content of the sediment (Table 1) (Adamiec and Aitken, 1998; Aitken, 1998; Brennan, 2003). The contribution of cosmic radiation to the dose rate was calculated using sample depth, elevation, and location (latitude and longitude) following Prescott and Hutton (1994), assuming a $10 \%$ error. Elemental abundances of U, Th, K and Rb were converted to a dose rate following Guérin (2011), assuming an additional 3\% error for the conversion of chemical data to dose rate (Murray and Olley, 2002). Finally, errors were calculated in quadrature, using the methods of Aitken and Allred (1972) and Aitken (1976, 1985).

\subsection{Equivalent-dose measurements}

\subsubsection{Optical parameters}

Optical measurements were performed on Risø OSL/TL DA-20 luminescence readers equipped with Sr ${ }^{90}$ beta radiation sources (0.13-0.16 Gy/sec dose rates). The purified quartz sand was mounted in a 2-mm diameter region ( $\sim 100$ grains per aliquot) on stainless steel disks with a silicone-based spray. Quartz grains were stimulated at $125{ }^{\circ} \mathrm{C}$ for $40 \mathrm{~s}$ with blue-green LEDs $(470 \mathrm{~nm})$ at $90 \%$ power $\left(36 \mathrm{~mW} / \mathrm{cm}^{2}\right)$. Photon detection was measured through a 7.5 mm U340 filter. The luminescence signal was calculated as the first $0.64 \mathrm{~s}$ of the resulting decay curve minus the background, which was averaged over the last 5 s. Examples of decay curves for five samples are shown in Fig. S1a. Fast ratio values (Durcan and Duller, 2011) indicate that the luminescence signals are dominated by the fast Component. 


\subsubsection{OSL measurements}

The single-aliquot regenerative-dose (SAR) method of Murray and Wintle (2000) was used to determine equivalent doses. In the SAR sequence, the natural luminescence signal was measured as well as the luminescence response to five regenerative doses, which included a repeated-dose and a zero-dose step. Dose-response data were fit with saturating exponential or saturating exponential plus linear curves (Fig S1b).

As part of the SAR sequence, samples were subject to a $10 \mathrm{~s}$ preheat $(\mathrm{PH})$ before measurement of the natural or regenerated luminescence. To investigate the influence of the measured De on PH temperature, dose-recovery and PH plateau tests were conducted. Three samples from fans (USU-251 from Upper Cedar Creek, USU-305 from Ramshorn, USU-645 from Birch Springs) and one from a terrace of the East Fork Big Lost River (USU-651) were selected for PH plateau and dose-recovery testing. These samples were selected to represent the possible variability in source-area lithology and ages of deposits and are assumed to be representative of the variability in luminescence response to $\mathrm{PH}$ temperatures. For the PH plateau test, 30-35 pristine aliquots of each sample were bleached at room temperature for $40 \mathrm{~s}$ at $90 \%$ blue-green LED power ( $36 \mathrm{~mW} / \mathrm{cm}^{2}$ ), followed by a $1000 \mathrm{~s}$ pause. This bleaching and pause was repeated a second time to ensure zeroing of the sample and equilibration of charge transfer prior to the next measurement. Aliquots were then given a beta dose similar to their natural dose and analyzed with $\mathrm{PH}$ temperatures ranging from 180-300 ${ }^{\circ} \mathrm{C}$ (held for $10 \mathrm{~s}$ ) at $20^{\circ} \mathrm{C}$ increments (5 aliquots per treatment step). For these measurements, cut-heat temperatures of $160^{\circ} \mathrm{C}$ (held for $0 \mathrm{~s}$ ) were used following 10-15 Gy test doses and optical measurements were at 125 ${ }^{\circ} \mathrm{C}$ at $36 \mathrm{~mW} / \mathrm{cm}^{2}$ LED power. Natural De doses were not used for the PH plateau test due to the large inter-aliquot variability in De values for many samples, which would obscure dependence on PH temperature. Dose-recovery tests followed similar procedures as the PH plateau tests and were performed using the most appropriate $\mathrm{PH}$ temperature identified in the PH plateau test.

\subsection{Bleaching test}

A bleaching test was conducted to aid in determining instrument and sediment-specific sources of variability and overdispersion in $D_{e}$ distributions. Pristine small aliquots of sample USU-250 were divided into ten subsets and exposed to direct sunlight for a range of times (0-960 s, 4-5 aliquots per exposure time). Aliquots were then given a 30 Gy dose to aid in the measurement of the low residual natural dose. The apparent De values were then measured using the same preheat and cut heat temperatures as used for dating LRR sediment. The 30 Gy additive dose was removed to allow for the calculation of the residual dose remaining following sunlight exposure.

\subsection{Calculation of ages and errors}

OSL ages for each sample were calculated using the central age model (CAM; Galbraith et al., 1999) from a minimum of 21 small aliquots of quartz sand ( 100 grains) that passed rejection criteria. Aliquots with recycling ratios or recuperation values $>10 \%$, a low signal to background noise ratio $(<3: 1)$, feldspar contamination (infrared stimulation response), and a natural $D_{e}$ value greater than the highest given regenerative dose were rejected and not included in age analysis. $\mathrm{D}_{\mathrm{e}}$ uncertainty was calculated at two-sigma standard error. Uncertainty in age estimates includes systematic and random errors from beta-source calibration, dose-rate estimation, and optical measurement errors according to the methods of Aitken and Alldred (1972) and Aitken $(1976,1985)$ and is presented as two-sigma standard error (Table 2).

\section{U-Series Methods}

Pebbles with coatings were cut, polished, and examined under low-power magnification to select samples from $\mathrm{CaCO}_{3}$ coatings that exhibited dark-colored, distinct laminae. Selected $\mathrm{CaCO}_{3}$ coat horizons were removed either by trenching around the desired area using a millimeter-diameter dental drill, or (for very thin rinds) by abrading the outer rind surface, chipping the rind from its clast, and abrading the inner rind surface.

Samples were dissolved completely in $\mathrm{HNO}_{3}-\mathrm{HF}-\mathrm{HClO}$, equilibrated with a mixed spike containing ${ }^{229} \mathrm{Th}$, ${ }^{233} \mathrm{U}$, and ${ }^{236} \mathrm{U}$. $\mathrm{U}$ and Th were separated using two stages of $\mathrm{HNO}_{3}-\mathrm{HCl}$ anion exchange chemistry. Purified $\mathrm{U}$ and $\mathrm{Th}$ fractions were loaded with colloidal graphite onto outgassed rhenium filaments and analyzed on a Micromass Sector54 TIMS equipped with a wide-angle, retarding-potential energy filter and Daly-type ion counter. Mass discrimination for $\mathrm{U}$ was corrected using the known ${ }^{233} \mathrm{U} /{ }^{236} \mathrm{U}$ ratio of the spike, whereas thorium ratios were uncorrected. The U-Th 
This is an author-produced, peer-reviewed version of this article. The final, definitive version of this document can be found online at Quaternary Geochronology, published by Elsevier. Copyright restrictions may apply. doi: 10.1016/j.quageo.2014.03.004

spike was calibrated against solutions of HU-1 (Harwell uraninite) standard and solutions of 69 Ma uranium ore from the Schwartzwalder Mine that have been demonstrated to yield concordant U/Pb ages (Ludwig et al., 1985) and sample-to-sample agreement of ${ }^{234} \mathrm{U} /{ }^{238} \mathrm{U}$ and ${ }^{230} \mathrm{Th} /{ }^{238} \mathrm{U}$ ratios. Procedural backgrounds for $\mathrm{m} / \mathrm{e}=230$ averaged $<0.15$ femtogram 230Th equivalent and were negligible for ${ }^{238} \mathrm{U}$ and ${ }^{232} \mathrm{Th}$. Ages were determined using the decay constants of Cheng et al. (2000). Ages and errors were calculated using Isoplot (Ludwig, 2003). Uncertainties associated with the detritus correction are propagated into the errors on age estimates.

High concentrations of ${ }^{232} \mathrm{Th}$ in the coatings (median $=0.27 \mathrm{ppm}$ ) indicate the presence of included detritus. Correction for $U$ and $T h$ isotopes from detritus is widely made by assuming detritus activity ratios of $\left({ }^{232} \mathrm{Th} /{ }^{238} \mathrm{U}\right)=1.2 \pm 0.6$, $\left({ }^{230} \mathrm{Th} /{ }^{238} \mathrm{U}\right)=1.0 \pm 0.25$, and $\left({ }^{234} \mathrm{U} /{ }^{238} \mathrm{U}\right)=1.0 \pm 0.25$, similar to average silicate crust (e.g. Ludwig and Paces, 2002). However, measured ${ }^{232} \mathrm{Th} /{ }^{238} \mathrm{U}$ ratios of detritus from the dated profiles, which are dominated by carbonate rocks, are much lower $\left[\left({ }^{232} \mathrm{Th} /{ }^{238} \mathrm{U}\right)\right.$ act. $\left.~ 0.4\right]$. Thus our preferred ages are calculated using the measured detritus values.

\section{OSL Characteristics}

\subsection{Dose-recovery preheat-plateau tests}

Based on the results from the pre-heat plateau tests (Fig. S2), $240{ }^{\circ} \mathrm{C}$ was selected as the most appropriate pre-heat temperature for LRR samples. Mean recovered doses for each sample were acceptable for a PH temperature of 240 ${ }^{\circ} \mathrm{C}$ for $10 \mathrm{~s}$, ranging from 93-107\% of the given dose (Fig. S2a). Recycling ratios (based on the same regenerative dose given at the beginning and end of the SAR sequence) showed little dependence on temperature (Fig. S2b), suggesting that corrections for sensitivity changes were appropriate. In addition, recuperation values (determined through administration of a zero dose) were low, $\sim 2-7 \%$ of the given dose, with a $240{ }^{\circ} \mathrm{C}$ pre-heat (Fig. S2c).

In dose-recovery tests, mean recovered doses for the three alluvial fan samples (USU-251, USU-305, and USU-645) were within $10 \%$ of unity (Fig. S2d), suggesting that use of the $240{ }^{\circ} \mathrm{C}$ preheat in the SAR protocol is indeed suitable for LRR samples. Overdispersion (OD) in the $\mathrm{D}_{\mathrm{e}}$ distributions for these dose-recovery tests at $240{ }^{\circ} \mathrm{C}$ ranged from 5$14 \%$ (Fig. S2d). Recovered doses showed greater variation for USU-651, the river terrace sample, ranging from 75$159 \%$ of the given dose for individual aliquots (mean of $103 \pm 27 \%$ ). This increased variability may reflect the different lithology of the terrace sediments as the East Fork Big Lost River drains the Pioneer Mountains to the east. However, only two of 34 total samples were collected from the East Fork Big Lost River.

\subsection{Bleaching experiment}

\section{Insert Figure 3 here}

Results from the bleaching test conducted on sample USU-250 show that, as expected, the measured OSL signal decreased with increased sunlight exposure time (Fig. 3a), with approximately 78\% of the natural dose (132 $\pm 11 \mathrm{~Gy}$ ) removed (bleached) after $2 \mathrm{~s}$ of exposure, 93\% after $15 \mathrm{~s}$, and $100 \%$ after $120 \mathrm{~s}$ of exposure. Two $\mathrm{D}_{\mathrm{e}}$ distributions were constructed from these results; one for partially bleached aliquots ( $<60 \mathrm{~s}$ exposure) and another for the wellbleached aliquots ( $>60 \mathrm{~s}$ exposure). Resulting $\mathrm{D}_{\mathrm{e}}$ distributions (Fig. $3 \mathrm{~b}$ and $\mathrm{c}$ ) were checked for significant positive skew (following Arnold et al., 2007) which can indicate partial bleaching (e.g. Olley et al., 1998, 1999; Lepper and McKeever, 2002). Skewness for only well-bleached aliquots (1.20) was not significant while skewness for all aliquots (2.27) was significantly positive. The overdispersion (OD) and kurtosis of each distribution was also calculated because distributions broader than expected can result from sources of error other than partial bleaching (e.g. Kalchgruber et al., 2003). OD and kurtosis (7.1\% and 1.98, respectively) for the well bleached aliquots were not significant. However, OD and kurtosis (32.6\% and 5.95, respectively) were both significant for the $\mathrm{D}_{\mathrm{e}}$ distribution when aliquots contained a range of bleaching exposures.

Results from what were considered to be well-bleached aliquots (>60s sunlight exposure) were used to inform the minimum possible OD values attainable for these sediments (7.1\% OD) and are similar to OD values obtained in the dose-recovery tests (4.9-13.8\% OD). This range in OD values suggests the minimum possible OD obtainable due to instrument error and sample- specific properties. Based on the results of the artificially partially bleached distribution, we have used OD $>30 \%$ and significant positive skew (following Arnold et al. 2007) as an indicator of partial bleaching in these sediments. 


\subsection{Influence of grain-size fraction on dose rate}

The influence of the contribution of different grain-sizes to the dose rate was investigated. Results indicate that the sand-sized fractions $(<2 \mathrm{~mm}$ and $0.15-2 \mathrm{~mm}$ ) produced the highest calculated dose rates (Fig. 4). The pebble-size fraction generally produced the lowest dose rates (Fig. 4 and 5), likely because they were predominantly composed of low-dose carbonate lithologies. Dose-rates derived from bulk samples were generally intermediate between those derived from the sand and pebble-sized fractions due to inclusion of both grain-size fractions (Fig. 4). For bulk samples, results from ICP-MS/ICP-AES analysis of pulverized material and gamma spectrometry of intact bulk samples are not substantially or systematically different (Fig. 4).

\section{Insert Figure 4 here.}

Insert Figure 5, here.

The dependence of dose rate on the grain-size fraction analyzed likely results from slight differences in the lithology between the coarse $(>2 \mathrm{~mm})$ and fine $(<2 \mathrm{~mm})$ fractions. The majority of $>2 \mathrm{~mm}$ grains in the fan deposits are composed of carbonate lithologies, which produced lower dose rates due to lower concentrations of $\mathrm{K}$, $\mathrm{U}$, and Th as seen in our analysis (rocks/ pebbles in Fig. 4). While the $<2 \mathrm{~mm}$ fraction is also predominately carbonate as determined by visual identification and reaction to $\mathrm{HCl}$, slight differences in lithology for this fraction likely produce the increased $\mathrm{K}, \mathrm{U}$, Th, and $\mathrm{Rb}$ concentrations and thus increased dose rate contribution. Lithological differences may be partially attributable to the incorporation of loess into the $<2 \mathrm{~mm}$ fraction during deposition, as loess deposits mantle alluvial surfaces throughout the basin (Patterson, 2006; Pierce and Scott, 1982). Concentration of heavy minerals during sediment transport along with concentration of minerals more resistant to weathering may also lead to the differences in lithology of the $<2 \mathrm{~mm}$ fraction. Increased $\mathrm{K}, \mathrm{U}$, Th and $\mathrm{Rb}$ concentrations in the fine fraction result in a greater dose rate contribution per volume from the fine sediment in comparison to the low dose rate carbonate pebbles and cobbles within the deposit.

While fluvial deposits are not typically homogenous, coarse-grained deposits can introduce additional heterogeneity in the beta dose-rate environment. For example, Hülle et al. (2009) encountered problems in how to best determine dose rates for heterogeneous sediment, even when in situ measurements were used. In addition, Nathan et al. (2003) showed that variability in grain-size and sediment composition could lead to significant heterogeneity in the portion of the dose derived from beta radiation, and suggest that careful consideration is required in determining what portions of the sediment to include for analysis. For LRR samples, we used the dose rate values obtained from bulk sediment in the OSL age calculation for samples where bulk dose-rate samples were obtained (Table 1). While the $<2 \mathrm{~mm}$ fraction likely provides the majority of the dose in the LRR deposits, use of only this fraction to estimate dose rate would neglect dilution of the overall dose by the $>2 \mathrm{~mm}$ fraction that makes up the majority of deposit volume. For locations where a bulk dose-rate sample was not collected the dose rate used in age calculations is based on an average of measurements of the $<2 \mathrm{~mm}$ fraction and the $125-2000 \mu \mathrm{m}$ fraction with an additional $25 \%$ uncertainty added to the dose rate error to account for observed differences between the $<2 \mathrm{~mm}$ and bulk sediment analyzed in other samples. The accuracy of these ages is discussed in sections 6.2 and 6.3 in relationship to other OSL ages and external age control.

\section{Insert Table 1 here}

Uncertainties in dose-rate estimation lead to increased uncertainty in the resulting luminescence age. Luminescence ages are calculated by dividing the $\mathrm{D}_{\mathrm{e}}$ by the dose rate. As a result, dose rate overestimates produce age underestimates while dose rate underestimates produce age overestimates. For the LRR, this indicates that resulting age estimates will be sensitive to the grain sizes included in dose rate estimation. Ages calculated from dose rates based only on sand fractions (Table 1) will likely underestimate true ages because this grain-size yields a higher dose rate than the bulk deposit (Figs. 4 and 5).

\subsection{Equivalent dose distributions}

The $\mathrm{D}_{\mathrm{e}}$ distributions from LRR fan samples were investigated for evidence of partial bleaching and dose-rate heterogeneity. Figure 6 shows five examples of $D_{e}$ distributions represented as histograms, cumulative probability distributions and radial plots. Examples were chosen to represent results from both traditional samples collected from 
thick sand lenses and samples excavated from coarse-grained sheet flood deposits as well as a range of resulting age estimates. In addition, various statistical metrics (mean:median ratio, skew, kurtosis and overdispersion) for $\mathrm{D}_{\mathrm{e}}$ distributions are shown in Figure 6 and presented in Table 2.

\section{Insert Figure 6 here.}

\section{Insert Table 2 here}

To help detect partial bleaching, small aliquots of sand ( 100 grains) were analyzed to decrease averaging effects from grains with different bleaching histories and increase the chance of identifying grains zeroed at deposition (Olley et al., 1998,1999; Wallinga, 2002). Resulting $\mathrm{D}_{\mathrm{e}}$ distributions were checked for OD > 30\% and significant positive skew caused by the presence of grains with residual signal (e.g. Olley et al., 1998, 1999; Lepper and McKeever, 2002). None of the traditionally collected samples were significantly skewed, but four samples excavated from sheetflood deposits had significant positive skew (USU-647, USU-704, USU- 649; Table 2 and Fig. 6). Analysis of $\mathrm{D}_{\mathrm{e}}(\mathrm{t})$ plots was also used to check for partial bleaching (Bailey et al, 2003) and evidence of unstable intermediate components (Jain et al., 2003). Poorly bleached grains are thought to retain more residual signal in the less light sensitive medium and slowly decaying components, producing greater $\mathrm{D}_{\mathrm{e}}$ estimates if later portions of the signal decay curve are integrated. Alternately, falling $\mathrm{D}_{\mathrm{e}}(\mathrm{t})$ plots may suggest the presence of unstable components (e.g. Jain et al. 2003).

Representative $\mathrm{D}_{\mathrm{e}}(\mathrm{t})$ analysis results from two samples, one from sheetflood gravels and with high positive skew (USU-652) and one sample traditionally collected from a sand lens (USU- 421) are shown in Figure S3. $\mathrm{D}_{\mathrm{e}}(\mathrm{t})$ results for natural and regenerative doses for these and other samples are similar for all portions of the decay curve and do not show significant increase with integration time as would be expected for poorly bleached samples. However, it should be noted that other studies suggest that this may not be a good indicator of partial bleaching as the stability of the medium component can influence results (Wallinga, 2002; Jain et al., 2003).

$\mathrm{D}_{\mathrm{e}}$ scatter not attributable to partial bleaching or instrument error, such as sediment mixing after deposition or heterogeneity in the dose rate, may be indicated by $D_{e}$ distributions that are broader than expected for a normal distribution (e.g. Kalchgruber et al., 2003). Significant negative kurtosis (at the $1 \sigma$ level) and overdispersion (OD) values greater than a critical value were interpreted as indicators of additional sources of $\mathrm{D}_{\mathrm{e}}$ scatter. Overdispersion values up to $20 \%$ have been observed for well-bleached samples (e.g. Roberts et al., 1998; Jacobs et al., 2003 a,b, 2006; Olley et al., 2004 a,b; Galbraith et al., 2005). Results from the dose-recovery test suggest that OD values up to $14 \%$ may be intrinsic to LRR sediment and instrument error.

Bleaching test results for sample USU-250 (Fig. 3) suggest that 30\% OD is an appropriate critical value for identifying significant $\mathrm{D}_{\mathrm{e}}$ scatter due to partial bleaching, dose-rate heterogeneity or other factors such as post-depositional mixing. Inclusion of only the well- bleached aliquots from the test ( $>60 \mathrm{~s}$ sunlight exposure) produced a $\mathrm{D}_{\mathrm{e}}$ distribution with non- significant OD of 7.1\%. Generation of an artificial partially-bleached distribution by including all aliquots (1-960 s sunlight exposure) produced a $\mathrm{D}_{\mathrm{e}}$ distribution with significant OD of 32.6\% and positive skew.

In order to examine the cause of $\mathrm{D}_{\mathrm{e}}$ scatter, the OD, skew and kurtosis of the resultant $\mathrm{D}_{\mathrm{e}}$ distributions were examined. While four of the 34 total samples had significant positive skew (11.7\%), seven of the samples (20.5\%) displayed significant negative kurtosis at the level $\sigma$ (following Arnold et al. 2007), and only two samples had OD $>30 \%$. None of the samples had significant skew, kurtosis and OD $>30 \%$ together. While significant positive skew can be attributed to partial bleaching, significant kurtosis and high OD may also be attributed to post- deposition mixing and dose-rate heterogeneity.

The greatest source of the significant negative kurtosis and high OD observed for many of the LRR samples is likely due to variability in microdosimetry. Partial bleaching is not interpreted to be a significant source of $\mathrm{D}_{\text {e }}$ scatter because few samples have significant positive skew. Post-deposition mixing is also not likely a significant source of $\mathrm{D}_{\mathrm{e}}$ scatter (kurtosis or OD) as care was taken to collect samples from $>1 \mathrm{~m}$ depth in undisturbed coarse-grained deposits (except for USU-419 which was collected from a soil underlying a tephra deposit). Numerous studies using small or singlegrain aliquots have suggested that heterogeneity in the dose contribution of the sediment, particularly in the beta dose, can produce variability in measured $\mathrm{D}_{\mathrm{e}}$ values (e.g. Olley et al., 1997; Murray and Roberts, 1997; Kalchgruber et al., 2003; Nathan et al., 2003; Vandenberghe et al., 2003; Mayya et al., 2006). 
The small number of samples collected from sand lenses in alluvial fan deposits in this study makes meaningful statistical comparison with samples from the more poorly sorted sheetflood deposits difficult. However, our results suggest that sheetflood deposits are more likely than sand lenses to produce $\mathrm{D}_{\mathrm{e}}$ distributions with significant skew, kurtosis or OD (Fig. 7 and Table 2). Three of seven sand lens samples, or 43\%, (excluding samples from the East Fork Big Lost River Terraces, which have different lithology) have significant skew, kurtosis, or OD while 14 of 25, or $56 \%$, of sheetflood samples have significant skew, kurtosis, or OD. The most probable explanation for this difference is the greater influence of grain-size dependent heterogeneity in the beta dose rate for the sheetflood gravels compared to the more homogeneous sand lenses.

\section{Insert Figure 7 here.}

In addition to grain-size and lithologic influences, accumulation of pedogenic carbonate can also produce differences in microdosimetry (e.g. Nathan and Mauz, 2008). While care was taken to avoid collecting samples from locations with carbonate accumulation, the inclusion of clasts with thin, discontinuous coatings was often unavoidable as carbonate accumulation was observed to depths exceeding three meters (the base of excavated trenches). Grains in areas with more significant carbonate accumulation would likely experience a decrease in dose rate through their burial history due to the diluting effect of low dose-rate carbonate.

Given the absence of strong evidence for partial bleaching, we did not use the minimum age model (MAM; Galbraith et al., 1999) in age calculations. Instead, a weighted mean using the central age model (CAM) of Galbraith et al. (1999) was considered the most appropriate method for analysis of samples with broad De distributions and significant OD or kurtosis.

\section{Results and Discussion}

\subsection{Analysis of resulting OSL age estimates}

Insert Figure 8 here

OSL age estimates from LRR alluvial fans and two terraces of the East Fork Big Lost River suggest deposition between $\sim 4-120$ ka (Fig. 8). Despite differences between samples in the grain-size fraction analyzed for dose-rate calculation, the resulting ages produce internally consistent results that preserve geomorphic and stratigraphic order. Where multiple samples were collected from a single site, the resulting ages are in good agreement. For example, samples were collected from depths of $1.6 \mathrm{~m}$ (USU-650) and $2 \mathrm{~m}$ (USU-649) at site 22 (Fig. 9a) on Ramshorn fan (Fig. 2b). Dose rates for both samples are derived from bulk sediment samples. While resulting central ages suggest a minor age reversal (25.0 \pm 3.6 ka over $23.2 \pm 2.9 \mathrm{ka})$, the ages are within error, as expected for samples from similar depths. A second example comes from site 4 on Birch Springs Fan where four OSL samples were collected (Fig. 9b). Bulk samples for dose rate analysis were not collected, so all dose rates at this site are based on the $<2 \mathrm{~mm}$ fraction. Resulting ages are $\sim 26-31$ ka and are in good agreement with each other and samples from the Qaf3 geomorphic fan surface (and Qa3 alluvial fill) elsewhere (Fig. 8, 9b).

\section{Insert Figure 9 here.}

Agreement in age estimates for samples collected from different locations on the same fan surface also suggest that OSL dating performs well for these deposits. For example, the single large surface of the Willow Creek fan was sampled in two locations (USU-412, site 1; USU-413, site 2; Fig. 2a) with good agreement in the resulting ages (14.4 $\pm 3.9 \mathrm{ka}$ and $13.9 \pm 4.0 \mathrm{ka}$, respectively), using the $<2 \mathrm{~mm}$ fraction for dose-rate determination. Three samples from different locations of a younger surface of Upper Cedar Creek fan (Qaf ${ }_{1}$, USU-251 at site 7, USU-417 at site 8, and USU-419 at site 9; Fig. 2c) all produce Holocene ages between 4-9 ka. One sample was collected by tube from a thick sand lens (USU-251) and the other two excavated from thin sand lenses (Table 2), all used bulk sediment for doserate analysis. Three samples from an older surface of Upper Cedar Creek Fan (Qaf 3 , USU-299 and USU-300, site 11; USU-301, site 13) all return ages between 23-26 ka (dose-rate analyzed from bulk sediment collected from coarse sheetflood deposits). Finally, age estimates for two samples from a single surface of King Canyon Fan (Qaf 2 , USU422, site 24; USU-655, site 25; Fig. 2b) are in good agreement (13.9 \pm 4.0 ka and $13.2 \pm 2.3$ ka, respectively; Table 2) despite differences in the grains sizes used for dose-rates estimates ( $<2 \mathrm{~mm}$ for USU-422 and bulk sample for USU655; Table 1). 
Despite overall consistency of OSL ages with the geomorphic and stratigraphic relationships, at site 14 on Upper Cedar Creek Fan there is an age reversal (Fig. S4). Two samples (USU-416 and USU-302) collected from a $30 \mathrm{~m}$ exposure show reasonable agreement in resulting ages $(116.1 \pm 20.6 \mathrm{ka}$ and $95.8 \pm 11.2 \mathrm{ka})$ but central ages are reversed based on the stratigraphic relationship. Analysis of sediment chemistry for dose rate estimation suggests a problem with U/Th disequilibrium for USU-416, as identified by a low Th:U ratio. While the greater $D_{e}$ of USU-302 is consistent with its stratigraphic position as the older sample, potential dose-rate disequilibrium in USU-416 likely produces the reversal in age estimates.

\subsection{Comparisons to external age control}

The overall geomorphic and stratigraphic coherence of OSL ages indicates that they are internally consistent. However, comparison with independent ages is required to identify possible systematic errors such as those related to dose rate estimation. Independent age control is available at site 9 on Upper Cedar Creek Fan (Fig. 2) where sediment exposed in an incised channel revealed a 3-4 cm thick tephra deposited $1 \mathrm{~m}$ below the modern land surface (Fig. 10). The tephra was overlain by pebble-cobble gravel sheetflood deposits capped by the modern soil. Loess accumulation and infiltration reached $22 \mathrm{~cm}$ depth and pedogenic carbonate accumulation was at developmental stage II (e.g. Giles, 1966). Immediately below the tephra was a buried soil, characterized by increased silt to fine sand that decreased with depth into distinct sheetflood deposits. This resembles modern soils in which loess accumulates at the surface and mixes to some depth with the underlying gravels. OSL sample USU-419 was excavated from this buried soil $20 \mathrm{~cm}$ below the tephra and dose rate was determined from a bulk sample of the surrounding sediment. Samples of the tephra were analyzed by electron microprobe (Washington State University) and ICP-MS analysis (Boise State University) for provenance. Results indicate the tephra originated from the $7627 \pm 150 \mathrm{cal}$ yr BP (Zdanowicz et al., 1999) eruption of Mt. Mazama that formed present-day Crater Lake in Oregon, USA ( $700 \mathrm{~km}$ west of the LRR). The resulting OSL age of $9.86 \pm 1.16 \mathrm{ka}$ is consistent with the tephra age and the stratigraphic position of the OSL sample below the tephra and soil horizon. Although this OSL sample was collected from a buried soil rather than unaltered fan gravels typical of other LRR samples, the deposit still contained a highly heterogeneous grain size distribution and the results confirm the applicability of OSL dating to these deposits.

\section{Insert Figure 10 here.}

Rough age estimates for the timing of fan-surface stabilization have been determined from the thickness of pedogenic carbonate coats on the undersides of clasts within soil profiles at some sites (Pierce and Scott, 1982; Vincent et al., 1994; Patterson, 2006). Measured coat thicknesses and limited U-series dating in the southern portion of the LRR (Pierce, 1985) suggest an average accumulation rate for pedogenic carbonate coats in the LRR of $0.06 \mathrm{~mm} / 10 \mathrm{ka}$. Based on this accumulation rate, Pierce and Scott (1982) estimated late Pleistocene deposition for many LRR fan surfaces. Patterson (2006) applied the same accumulation rate to place the timing of surface stabilization at $28 \pm 20 \mathrm{ka}$ for sites 11 and 13 on Upper Cedar Creek Fan $\left(\mathrm{Qaf}_{3}\right)$. This timing is consistent with the OSL ages from these sites of $23.6 \pm 3.3 \mathrm{ka}$ (site 11, USU-299), $27.2 \pm 3.7 \mathrm{ka}$ (site 11, USU-300), and $26.3 \pm 3.6 \mathrm{ka}$ (site 13, USU-301). Although the uncertainty on the carbonate-coat derived ages is too large to provide a rigorous assessment of our OSL ages, the two methods do show good agreement.

\subsection{U-series results}

In coarse alluvium, the initial stages of pedogenic carbonate accumulation include formation of coatings on the undersides of gravel clasts. Such clast-coatings, if dense and relatively free of contamination by detritus, can be suitable for U-series dating (e.g., Ku et al., 1979; Pierce 1985; Ludwig and Paces, 2002). Datable thicknesses of clastcoatings may accumulate in 1 ka or less (e.g., Blisniuk et al., 2012). Therefore, U-series dating of carbonate coatings provides a minimum estimate of the depositional age of host LRR fan-gravels. Below, we compare U-series and OSL dates from two sites on LRR alluvial fans. U-series results are reported in Table 3 and plotted in Figure 11.

\section{Insert Table 3 here.}

On the Ramshorn fan at site 19, we dated seven clast-coatings by U-series from four different soil horizons (BW, Bk1, $\mathrm{Bk} 2$, and Bk3). One sample from the BW horizon (RH2-1BW) was rejected because it yielded a highly imprecise age estimate $(43.9 \pm 13.4 \mathrm{ka})$ due to a large detritus correction. The remaining six samples from three soil horizons at this site yield preferred ages of $10.2 \pm 2.4$ ka to $18.4 \pm 5.6 \mathrm{ka}$. The weighted mean of these results is $12.8 \pm 1.1 \mathrm{ka}$ ( 2 error, 
This is an author-produced, peer-reviewed version of this article. The final, definitive version of this document can be found online at Quaternary Geochronology, published by Elsevier. Copyright restrictions may apply. doi: 10.1016/j.quageo.2014.03.004

$\mathrm{n}=6$, MSWD $=2.9$ ). The mean U-series age is in good agreement with the OSL age from the same trench of $15.6 \pm$ 5.0 ka (USU-306) (Fig. 11a). The older OSL age of the deposit and younger U-series age for pedogenic carbonate precipitation indicates that surface stabilization and/or soil development could have begun very quickly or up to $10 \mathrm{ka}$ after sediment deposition. We note that this OSL age was established from an alluvial sheetflood deposit using a dose rate determined from the average value of the sand sized fraction. The concordant OSL and U-series ages suggest no systematic bias between techniques.

On the Birch Springs fan at site 6, six U-series samples give preferred ages of $2.3 \pm 13.2 \mathrm{ka}$ to $23.6 \pm 5.2 \mathrm{ka}$. The oldest three ages, $19.2 \pm 8.6 \mathrm{ka}, 21.5 \pm 3.0 \mathrm{ka}$, and $23.6 \pm 5.2 \mathrm{ka}$, are in mutual agreement and their weighted mean age is $21.8 \pm 2.4 \mathrm{ka}(\mathrm{n}=3$, MSWD $=0.43)$. The $\mathrm{U}$ - series age is significantly younger than the age of OSL sample USU-704 from the same site ( $47.3 \pm 4.6 \mathrm{ka})$, which was determined on sheetflood gravels using a dose rate from a bulk sample (see Fig. 11). We note that an age of 22 ka for this Qaf4 surface is inconsistent with its relative geomorphic position (see Fig. 2 and 11b). In this case, we speculate that (1) the U-series age reflects surface erosion and a younger period of soil formation, or (2) that early-formed carbonate was not preserved or was not sampled at this site, or (3) the effective averaging of sub- millimeter younger carbonate coating laminae with older laminae in each sample produce younger apparent ages for the coats.

\subsection{Fill-cut terraces identified through OSL dating}

In three locations OSL ages from geomorphically lower surfaces produced older ages than samples from geomorphically higher surfaces. These situations are most logically explained as instances of fill-cut terrace formation, or alluvial straths, in which vertically stacked deposits are incised and older deposits are exposed at depth under younger fan channels (Fig. 11). Morphology of LRR fans indicates that they are stacked fans where deposits have accumulated vertically rather than in an inset and telescoping manner. We interpret that one alluvial strath is located in a small incised channel on the Ramshorn fan at site 18 (Fig.2b, 11a). The geomorphically higher surfaces produced OSL ages of $15.6 \pm 5.0 \mathrm{ka}$ (site 19, $\mathrm{Qaf}_{2}$ ) and $23.2 \pm 2.9 \mathrm{ka}$ and $25.0 \pm 3.6 \mathrm{ka}$ (site 22, Qaf 3 ), but the geomorphically lower inset channel surface of site 18 produces a much older OSL age of $39.6 \pm 12.8$ ka (USU-305). This inset channel is interpreted to be an alluvial strath surface cut into the older fill deposits $\left(\mathrm{Qa}_{3}\right)$ underlying the $\mathrm{Qaf}_{3}$ surface elsewhere on the fan (Fig 2b, 11a). Such alluvial straths are common in alluvial fan and fluvial terrace sequences, where they are commonly called fill-cut terraces (e.g. Schumm, 1977).

\section{Insert Figure 11 here.}

OSL ages suggest the presence of a second alluvial strath surface at site 5 on the Birch Springs Fan where, despite a $\sim 12 \mathrm{~m}$ height difference between site 5 (inset fan surface) and site 6 ( $\mathrm{Qaf}_{4}$ fan surface), OSL samples produce similar ages of $47.0 \pm 5.5 \mathrm{ka}$ (site 5, USU-703) and $47.0 \pm 6.5 \mathrm{ka}$ (site 6, USU-704) (Fig. 11b). These similar OSL ages (both calculated using bulk sediment for dose-rate analysis) suggest rapid aggradation of the Qa4 fill $\sim 47 \mathrm{ka}$, with later incision to form the alluvial strath upon which site 5 sits. A third probable alluvial strath occurs on the King Canyon Fan at sites 23, and 26 (Fig. 11c). Samples collected from the geomorphically higher surface of sites 24 and 25 (Qaf $_{2}$ fan surface) produced OSL ages of $13.9 \pm 4.0 \mathrm{ka}$ and $13.2 \pm 2.3 \mathrm{ka}$, respectively, while a sample from site 26 from the inset Qaf 1 surface produced an age of $20.8 \pm 2.7 \mathrm{ka}$ (USU-656) with little evidence of partial bleaching. Site 23 sits on the same geomorphic surface as site 26 but produces an age of $8.1 \pm 0.7 \mathrm{ka}$. This sample was collected at only 1 $\mathrm{m}$ depth from a finer-grained unit and is interpreted as a thin and younger deposit capping the alluvial strath.

Problems with OSL samples such as partial bleaching or dose rate heterogeneity could potentially produce age reversals as well. However, as discussed in section $5.4, \mathrm{D}_{\mathrm{e}}$ distributions do not indicate significant problems with partial bleaching (i.e. significant positive skew). Dose-rate heterogeneity would likely produce ages with greater uncertainty due to increased variability in $\mathrm{D}_{\mathrm{e}}$ estimates rather than entirely inaccurate ages. However, inaccurate ages may result from samples where dose-rate estimates were not based on bulk sediment samples. At Ramshorn Fan, the OSL sample from site 18 on the alluvial strath does indeed lack a bulk sample for dose-rate estimation. As discussed in section 5.3, dose rates based on bulk sediment samples produce lower dose rate estimates and thus older estimated ages than dose rate and age estimates based on only the $<2 \mathrm{~mm}$ grain size fraction (Fig. 4). This suggests that consideration of a bulk sediment sample for dose rate estimation at site 18 would produce an age $>39$ ka, but an older age would not change our interpretation of this surface as an alluvial strath (Fig. 11a). At King Canyon Fan, we lack a bulk sediment sample for dose rate estimation for site 24, suggesting that the OSL age of $13.9 \pm 4.0$ ka may be an underestimate. However, the OSL sample from site 25 is located on the same surface as site 24, (Figs. 2b and 11c) 
produces an age in good agreement of $13.2 \pm 2.3 \mathrm{ka}$ and was calculated with a dose rate based on a bulk sediment sample. In our view, the ages from these three locations are most readily explained by the presence of an alluvial strath causing old deposits to be exposed on a young geomorphic surface.

\section{Conclusions}

The major goals of this study were to (1) investigate heterogeneity in the dose-rate contribution of different grain-size fractions, (2) examine potential sources of skewness, kurtosis, or overdispersion in $\mathrm{D}_{\mathrm{e}}$ distributions for coarse-grained deposits, (3) compare OSL ages for timing of deposition with U-series ages for timing of surface stabilization, and (4) assess the reliability of age estimates using independent ages and stratigraphic relationships. Pertaining to the first goal, our results suggest that optical dating can be successfully applied to coarse-grained fluvial deposits that lack sand lenses. Sampling strategies that do not involve sample tubes can easily be devised, but dose-rate estimates may require more consideration due to sediment heterogeneity. For LRR alluvial fans, results show that the $<2 \mathrm{~mm}$ portion contributes more to the dose-rate than the coarse fraction and, due to this heterogeneity, bulk samples with all sizes present in correct portions were considered to give the best estimates of dose-rate. Further, this sediment heterogeneity likely contributes to significant skewness, kurtosis, and overdispersion that characterized $56 \%$ of the $\mathrm{D}_{\mathrm{e}}$ distributions for coarser, sheetflood deposits (the second goal). While success of the U-series dating was limited to two sites, the resulting OSL and U-series ages at these locations were in agreement, supporting the applicability of OSL dating to coarser deposits that lack sand lenses. We accomplish the fourth goal by identifying six periods of fan aggradation over the last $120 \mathrm{ka}$. Resulting ages show good agreement with the known age for an identified ash layer and good reproducibility for individual exposures and fan surfaces. Other users who wish to apply optical dating to similar coarse-grained deposits may also want to analyze several grain sizes as well as bulk samples to identify dose-rate heterogeneity. This study provides an improved understanding of the extent to which dose rates are influenced by grain-size distributions, and therefore, augments the ability of future researchers to apply OSL techniques to coarsegrained deposits.

\section{Acknowledgements}

Funding for this work was provided by the National Science Foundation (grant number NSFEAR-0720391). We would like to thank Shannon Mahan at the USGS Luminescence Laboratory in Denver, CO for her assistance in measuring bulk sediment chemistry; the Challis and Upper Snake BLM field offices for their cooperation; Washington State University's GeoAnalytical Lab, Dr. Shawn Benner and Paul Olin for their identification of the tephra sample; Dr. Ken Pierce, Ben Mcveigh, and Mike Poulos, for their contributions and assistance in the field; and Idaho State University Department of Geosciences for the use the Lost River Field Station facilities. We would also like to thank Dr. Matt Kohn for his helpful insight and discussion. This paper was substantially improved by thoughtful input from three anonymous reviewers. 


\section{References}

Adamiec, G., Aitken, M., 1998. Dose-rate conversion factors: update. Ancient TL 16, 37-50.

Aitken, M., 1998. An Introduction to Optical Dating. Oxford Science Publications, Oxford.

Aitken, M.J., 1976. Thermoluminescent age evaluation and assessment of error limits: revised system. Archaeometry 18, 233-238.

Aitken, M.J., 1985. Thermoluminescence Dating. Academic Press, London.

Aitken, M.J., and Alldred, J.C., 1972. The assessment of error limits in thermoluminescent dating. Archaeometry 14, 257-267.

Arnold, L.J., Bailey, R.M., Tucker, G.E., 2007. Statistical treatment of fluvial dose distributions from southern Colorado arroyo deposits. Quaternary Geochronology 2, 162-167.

Bailey, R.M., Singarayer, J.S., Ward, S., Stokes, S., 2003. Identification of partial resetting using $D_{e}$ as a function of illumination time. Radiation Measurements 37, 511-518.

Birkeland, P.W., Machette, M.N., Haller, K.M., 1991. Soils as a tool for applied Quaternary geology. Utah Geological and Mineral Survey miscellaneous publication 91-3, 63 p.

Blair, T.C., McPherson, J.G., 1994. Alluvial fans and their natural distinction from rivers based on morphology, hydraulic processes, sedimentary processes, and facies assemblages. Journal of Sedimentary Research 64, 450-489.

Blisniuk, K. Oskin, M., Fletcher K., Rockwell, T., Sharp, W., 2012. Assessing the Reliability of U-series and ${ }^{10}$ Be dating techniques on Alluvial Fans in the Anza Borrego Desert, California. Quaternary Geochronology 13, 26-41.

Brennan, B.J., 2008. Beta doses to spherical grains. Radiation Measurements 37, 299-303.

Cheng, H., Edwards, R.L., Hoff, J., Gallup, C.D., Richards, D.A., Asmerom, Y., 2000. The half-lives of uranium234 and Thorium-230. Chemical Geology 169, 1733.

Duller, G.A.T., 2004. Luminescence dating of quaternary sediments: recent advances. Journal of Quaternary Science 19, 183-192.

Duller, G.A.T., 2008. Single-grain optical dating of Quaternary sediments: why aliquot size matters in luminescence dating. Boreas 37, 589-612.

Durcan, J.A., Duller, G.A.T., 2011 The fast ratio: A rapid measure for testing the dominance of the fast component in the initial OSL signal from quartz. Radiation Measurements 46, 1065-1072.

Funk, J.M., 1976. Climatic and tectonic effects on alluvial fan systems, Birch Creek Valley, east central Idaho. Ph.D. thesis, University of Kansas.

Galbraith, R.F., Roberts, R.G., Laslett, G.M., Yoshida, H., Olley, J.M., 1999, Optical dating of single and multiple grains of quartz from Jinmium Rock Shelter, northern Australia: Part I, experimental design and statistical models. Archaeometry 41, 339-364.

Galbraith, R.F., Roberts, R.G., Yoshida, H., 2005. Error variation in OSL palaeodose estimates from single aliquots of quartz: a factorial experiment. Radiation Measurements 39, 289-307.

Giles, L.H., Peterson, F.F., Grossman, R.B., 1966. Morphological and genetic sequences of carbonate accumulation in desert soils. Soil Science 101, 347-360.

Goble, R.J., Mason, J.A., Loope, D.B., Swinehart, J.B., 2004. Optical and radiocarbon ages of stacked paleosols and dune sands in the Nebraska Sand Hills, USA. uaternary Science Reviews 23, 1173-1182.

Gosse, J., Phillips, F.M., 2001. Terrestrial in situ cosmogenic nuclides: Theory and application. Quaternary Science Reviews 20, 1475-1560.

Guérin, G., Mercier, N., Adamiec, G., 2011. Dose-rate conversion factors: update. Ancient TL 29, 5-8.

Haller, K.M., Crone, A.J., 2004. Twenty Years After the Borah Peak Earthquake Field Guide to Surface-Faulting Earthquakes Along the Lost River Fault, Idaho. In Haller, K.M., and Wood, S.H. (Eds.), Geological Field Trips in Southern Idaho, Eastern Oregon, and Northern Nevada. U.S. Geological Survey Open File Report 2004-1222, pp. 119-135.

Hülle, D., Hilgers, A., Kühn, P., Radtke, U., 2009. The potential of optically stimulated luminescence for dating periglacial slope deposits: A case study from the Taunus area, Germany. Geomorphology 109, 66-78.

Huntley, D.J., McMullan, W.G., Godfrey-Smith, D.I., Thewalt, M.L.W., 1989. Time-dependent recombination spectra arising from optical ejection of trapped charges in feldspars. Journal of Luminescence 44, 41-46.

Jacobs, Z., Wintle, A.G., Duller, G.A.T., 2003a, Optical dating of dune sand from Blombos Cave, South Africa: I-multiple grain data. Journal of Human Evolution 44, 599-612.

Jacobs, Z., Duller, G.A.T., Wintle, A.G., 2003b. Optical dating of dune sand from Blombos Cave, South Africa: II-single grain data. Journal of Human Evolution 44, 613-625. 
Jacobs, Z., Duller, G.A.T., Wintle, A.G., 2006. Interpretation of single grain $\mathrm{D}_{\mathrm{e}}$ distributions and calculation of De. Radiation Measurements 41, 264277.

Jain, M., Murray, A.S., Botter-Jensen, L., 2004. Optically stimulated luminescence dating: How significant is incomplete light exposure in fluvial environments? Quaternaire 15, 143-157.

Jain, M., Murray, A.S., Bøtter-Jensen, L., 2003. Characterisation of blue-light stimulated luminescence components in different quartz samples: implications for dose measurement. Radiation Measurements 37, 441-449.

Kalchgruber, R., Fuchs, M., Murray, A.S., Wagner, G.A., 2003. Evaluating dose-rate distributions in natural sediments using $\alpha$ - Al2O3:C grains. Radiation Measurements 37, 293-297.

Ku, T.L., Bull, W.B., Freeman, S.T., Knauss, K.G., 1979. 230Th 234U dating of pedogenic carbonates in gravelly desert soils of Vidal Valley, southern California. Geological Society of America Bulletin 90, 1063-1073.

Lepper, K., W. S. McKeever, S., 2002. An Objective Methodology for Dose Distribution Analysis. Radiation Protection Dosimetry 101, 349-352.

Ludwig, K.R., 2003. Using Isoplot/Ex, Version 2.01: A Geochronological Toolkit for Microsoft Excel, Berkeley Geochronology Center Special Publication, 1a, 47 pp., Berkeley Geochronology Center, Berkeley, California.

Ludwig, K.R., Paces, J.B., 2002. Uranium-series dating of pedogenic silica and carbonate, Crater Flat, Nevada. Geochimica Cosmochimica Acta 66, 487-506.

Ludwig, K.R., Wallace, A.R., Simmons, K.R., 1985. The Schwartzwalder uranium deposit, II: age of uranium mineralization and Pb-isotope constraints on genesis. Economic Geology 80, 1858-1871.

Machette, M.N., 1985. Calcic soils of the southwestern United States. In Weide, D.L. (Ed.), Soils and Quaternary geology of the southwestern United States. Geological Society of America Special Paper 203, pp. 1-21.

Mayya, Y.S., Morthekai, P., Murari, M.K., Singhvi, A.K., 2006. Towards quantifying beta microdosimetric effects in single-grain quartz dose distribution. Radiation Measurements 41, 1032-1039.

Murray, A.S., Olley, J.M., 2002. Precision and accuracy in the optically stimulated luminescence dating of sedimentary quartz: A status review. Geochronometria 21, 1-16.

Murray, A.S., Roberts, R.G., 1997. Determining the burial time of single grains of quartz using optically stimulated luminescence. Earth and Planetary Science Letters 152, 163-180.

Murray, A.S., Wintle, A.G., 2000. Luminescence dating of quartz using an improved single-aliquot regenerativedose protocol. Radiation Measurements 32, 57-73.

Nathan, R.P., Mauz, B., 2008. On the dose-rate estimate of carbonate-rich sediments for trapped charge dating. Radiation Measurements 43, 14-25.

Nathan, R.P., Thomas, P.J., Jain, M., Murray, A.S., Rhodes, E.J., 2003. Environmental dose rate heterogeneity of beta radiation and its implications for luminescence dating: Monte Carlo modeling and experimental validation. Radiation Measurements 37, 305-313.

Olley, J., Caitcheon, G., Murray, A., 1998. The distribution of apparent dose as determined by Optically Stimulated Luminescence in small aliquots of fluvial quartz: Implications for dating young sediments. Quaternary Science Reviews 17, 1033-1040.

Olley, J.M., Caitcheon, G.G., Roberts, R.G., 1999. The origin of dose distributions in fluvial sediments, and the prospect of dating single grains from fluvial deposits using optically stimulated luminescence. Radiation Measurements 30, 207-217.

Olley, J.M., De Deckker, P., Roberts, R.G., Fifield, L.K., Yoshida, H., Hancock, G., 2004. Optical dating of deepsea sediments using single grains of quartz: a comparison with radiocarbon. Sedimentary Geology 169, 175-189.

Olley, J.M., Pietsch, T., Roberts, R.G., 2004. Optical dating of Holocene sediments from a variety of geomorphic settings using single grains of quartz. Geomorphology 60, 337-358.

Olley, J.M., Roberts, R.G., Murray, A.S., 1997. Disequilibria in the uranium decay series in sedimentary deposits at Allen's cave, nullarbor plain, Australia: Implications for dose rate determinations. Radiation Measurements 27, 433-443.

Patterson, S.J., 2006. Sedimentology and geomorphology of quaternary alluvial fans with implications to growth strata, Lost River Range. M.S. thesis, Montana State Univ. Bozeman, Montana.

Pierce, K.L., 1985. Quaternary history of movement on the Arco segment of the Lost River fault, central Idaho. In Stein, R.S., and Bucknam, R.C. (Eds.), Proceeding of Workshop XXVIII On the Borah Peak, Idaho, Earthquake Volume A, United States Geological Survey Open File Report 85-290.

Pierce, K.L., Colman, S.M., 1986. Effect of height and orientation (microclimate) on geomorphic degradation rates and processes, late glacial terrace scarps in central Idaho. Geological Society of America Bulletin 97, 869885. 
This is an author-produced, peer-reviewed version of this article. The final, definitive version of this document can be found online at Quaternary Geochronology, published by Elsevier. Copyright restrictions may apply. doi: 10.1016/j.quageo.2014.03.004

Pierce, K.L., Scott, W.E., 1982. Pleistocene episodes of alluvial-gravel deposition, southeastern Idaho. In Bonnichsen, B., and Breckenridge, R.M. (Eds.), Cenozoic geology of Idaho. Idaho Bureau of Mines and Geology Bulletin 26, pp. 685-702.

Prescott, J. R., Hutton, J. T.. 1994. Cosmic ray contributions to dose rates for luminescence and ESR dating: Large depths and long-term time variations. Radiation Measurements 23, 497-500.

Rittenour, T.M., 2008. Luminescence dating of fluvial deposits: applications to geomorphic, palaeoseismic and archaeological research. Boreas 37, 613-635.

Rizza, M., Mahan, S., Ritz, J.F., Nazari, H., Hollingsworth, J., Salamati, R.,2011. Using luminescence dating of coarse matrix material to estimate the slip rate of the Astaneh fault, Iran. Quaternary Geochronology 6, 390-406.

Roberts, R.G., Yoshida, H., Galbraith, R.F., Laslett, G.M., Jones, R., Smith, M., 1998. Singlealiquot and singlegrain optical dating confirm thermoluminescence age estimates at Malakunanja II rock shelter in northern Australia. Ancient TL 16, 19-24.

Schumm, S.A. 1977. The Fluvial System. Wiley, New York. 338 p.

Scott, W.E., Pierce, K.L., Hait, M.H., JR, 1985. Quaternary tectonic setting of the 1983 Borah Peak earthquake, central Idaho. Bulletin of the Seismological Society of America 75, 1053-1066.

Sharp, W.D., Ludwig, K.R., Chadwick, O.A., Amundson, R., Glaser, L.L., 2003. Dating fluvial terraces by 230Th/U on pedogenic carbonate, Wind River Basin, Wyoming. Quaternary Research 59, 139-150.

Skipp, B., Hait, M.H., JR, 1977. Allochtons along the northeast margin of the Snake River Plain, Idaho. Wyoming Geological Association Guidebook, pp. 499-515.

Truelsen, J.L., Wallinga, J., 2003. Zeroing of the OSL signal as a function of grain size: Investigating bleaching and thermal transfer for a young fluvial sample. Geochronometria 22, 1-8.

Vandenberghe, D., Hossain, S.M., De Corte, F., Van den haute, P., 2003. Investigations on the origin of the equivalent dose distribution in a Dutch coversand. Radiation Measurements 37, 433-439.

Vincent, K.R., W.B.Bull, Chadwick, O.A., 1994. Construction of a soil chronosequence using the thickness of pedogenic carbonate coatings. Journal of Geological Education 42, 316-324.

Wallinga, J., 2002. Optically stimulated luminescence dating of fluvial deposits: a review. Boreas 31, 303-322.

Zdanowicz, C.M., Zielinski, G.A., Germani, M.S., 1999. Mount Mazama eruption: Calendrical age verified and atmospheric impact assessed. Geology 27, 621-624. 


\section{Table Captions}

Table 1. Sample chemistry and resulting dose rates for luminescence samples. Site numbers refer to locations shown in Fig. 2.

Table 2. Optical ages for Lost River Range alluvial fans and terraces of the East Fork Big Lost River. Site numbers refer to locations in Fig. 2.

Table 3. U-series results from pedogenic carbonate coats from two sites on Lost River Range Fans. Site numbers refer to locations in Fig. 2.

\section{Figure Captions}

Figure 1. Location of the Lost River Range and Big Lost River Basin within the western U.S. and Idaho. Alluvial fans (thick outline) and contributing basins (thin outline) are highlighted; Willow Creek (WC), Birch Springs (BS), Upper Cedar Creek (UC), Ramshorn (RH), and King Canyon (KC).

Figure 2. Geomorphic maps of LRR alluvial fans and glacial moraines. Similar age surfaces were mapped based on geomorphic relationships, deposit characteristics, soil and pedogenic carbonate development, and OSL ages. Numbers refer to the location of sample sites discussed in text and tables.

Figure 3. Results of bleaching experiment test on USU-250 (sections 3.4 and 4.2). a) Relationship between duration of direct sunlight exposure and apparent De showing negligible residual signal for $\geq 60$ s exposure. $b$ ) Radial plot for individual $\mathrm{D}_{\mathrm{e}}$ results, grouped by aliquots with $\leq 60 \mathrm{~s}$ or $>60$ s of sunlight exposure. c) PDFs for all aliquots in bleaching test and those with $>60$ s sunlight exposure. Asterisks behind overdispersion (OD), skew and kurtosis values indicate significant values (following Arnold et al. 2007).

Figure 4. Dependence of dose rate on grain-size fraction analyzed for six samples. All samples except USU-644 are from sheetflood deposits sampled at night or under tarps; USU-644 was collected from a thin sand lens at night. Sample numbers are followed by the difference in estimated dose rate between the average of bulk sediment measurements and the average of $<2 \mathrm{~mm}$ fraction measurements.

Figure 5. Comparison of dose rates derived from the sand fraction and dose rates derived from bulk sediment samples with all grain sizes retained in correct proportions; while the sand fraction produces higher dose-rate estimates compared to bulk sediment samples, the results are largely within $10 \%$ of each other.

Figure 6. Examples of equivalent dose $\left(D_{e}\right)$ distributions show that samples from alluvial fans generally produce similar De distributions regardless of deposit type, collection method or age. (a) Sample information and relevant statistics for $\mathrm{D}_{\text {e }}$ distribution. Asterisk indicates significant value (Arnold et al., 2007). Age estimate from central age model (CAM; Galbraith et al., 1999). (b) $D_{e}$ distributions as histograms; arrow indicates $D_{e}$ estimate from CAM (Galbraith et al., 1999). (c) $D_{e}$ distributions as probability density plots of with individual $D_{e}$ measurements and errors overlain. Solid line: sum of weighted distributions. Dashed line: mean $\mathrm{D}_{\mathrm{e}} \pm 3$ standard deviations. (d) Radial plots for $\mathrm{D}_{\mathrm{e}}$ distributions.

Figure 7. Plots of overdispersion (OD) against (a) skew and (b) kurtosis for $\mathrm{D}_{\mathrm{e}}$ distributions. Filled symbols indicate significant values (Arnold et al., 2007). Samples from sheetflood deposits are more likely than those from sand lenses to have significant skew, kurtosis, or OD, likely due to increased grain-size dependent heterogeneity in the beta dose rate (section 4.4.)

Figure 8. Graphical display of resulting optical age estimates for the timing of sediment deposition on Lost River Range alluvial fans and two terraces of the East Fork Big Lost River. Periods of deposition of alluvial fills $\left(\mathrm{Qa}_{1}-\mathrm{Qa}_{4}\right)$ shown by shaded bars. 
This is an author-produced, peer-reviewed version of this article. The final, definitive version of this document can be found online at Quaternary Geochronology, published by Elsevier. Copyright restrictions may apply. doi: 10.1016/j.quageo.2014.03.004

Figure 9. Samples excavated from sheetflood deposits at night or under light-safe tarps at (a) site 22 on Ramshorn fan (USU-649 and USU-650) and (b) site 4 on Birch Springs fan (USU- 647, USU-415, USU-645 and USU-646). Resulting ages at each site show good agreement and minor age reversals may be due to factors such as dose-rate heterogeneity, sediment mixing after deposition or accumulation of pedogenic carbonate.

Figure 10. Stratigraphy of site 9 on Upper Cedar Creek fan showing Mazama tephra overlying a buried soil developed in alluvial gravels. OSL results for USU-419 (excavated at night, dose rate from bulksediment analysis) are consistent with the age of the overlying tephra (Zdanowicz, 1999) and a period of soil formation between deposition of the alluvial gravels and the tephra.

Figure 11. Illustration of the geomorphology and alluvial stratigraphy of (a) Ramshorn, (b) Birch Springs and (c) King Canyon alluvial fans. Relative positions of surfaces are shown but illustrations are not to scale. OSL ages from fan deposits and U-series ages of pedogenic carbonates are shown. Alluvial straths were inferred from OSL age estimates. These alluvial straths were formed through incision into older deposits that were subsequently sampled for OSL dating, producing an anomalously old age for a geomorphically lower surface. DR = dose rate.

\section{Supplemental Data Figure Captions}

Figure S1. (a) Signal-decay curves for representative natural and regenerative dose signals from five samples. Fast ratios (Durcan and Duller, 2011) indicate that samples are dominated by the fast-decaying luminescence component of quartz. (b) Dose-response curves for the same samples. The natural signal is shown as a square, regenerative doses shown as diamonds and a repeat dose shown as a open diamond. Data was fit with saturating exponential or saturating exponential plus linear curves.

Figure S2. Results from dose-recovery preheat-plateau tests for four alluvial fan samples and one East Fork Big Lost River terrace sample (4-5 aliquots per preheat temperature). Based on these results, a preheat temperature of $240{ }^{\circ} \mathrm{C}$ held for $10 \mathrm{~s}$ was selected. (a) Dependence of recovered dose on preheat temperature. (b) Recycling ratios for repeated doses at the beginning and end of the SAR sequence. (c) Recuperation of signal following a step with zero-applied dose, shown as percent of the given dose. (d) Dose-recovery test results for a preheat temperature of $240^{\circ} \mathrm{C}$. Mean values shown are based on results from 10 aliquots for all samples except USU-251, for which only 8 aliquots were measured, and USU-651 which is based on 9 aliquots after elimination of one aliquot that did not meet criteria for inclusion. Overdispersion (OD) or scatter in the recovered dose distributions are shown for each sample.

Figure S3. Examples of $D_{e}(t)$ plots used to check for partial bleaching and signal components (Bailey et al., 2003). USU-652 was collected by excavating sediment from a thin sand lens within a coarse-grained sheetflood deposit and while USU-421 was collected by pounding a metal tube into a thick sand lens. $\mathrm{D}_{\mathrm{e}}$ estimates for natural and regenerated doses for these and other samples are similar for integration of various portions of the signal decay curve, suggesting that the medium and slow components of the OSL sample are well bleached and partial bleaching of these components is not a concern.

Figure S4. The $\sim 30 \mathrm{~m}$ exposure at site 14 on Upper Cedar Creek alluvial fan with the locations of two OSL samples: USU-416 from $\sim 15 \mathrm{~m}$ below the surface and USU-302 from $20 \mathrm{~m}$ below the surface. While the central age estimates are stratigraphically reversed, the equivalent doses are consistent with depth. The age reversal likely results from U/Th disequilibrium in the dose rate as suggested by excess of $U$ in relation to Th (Table 1). 


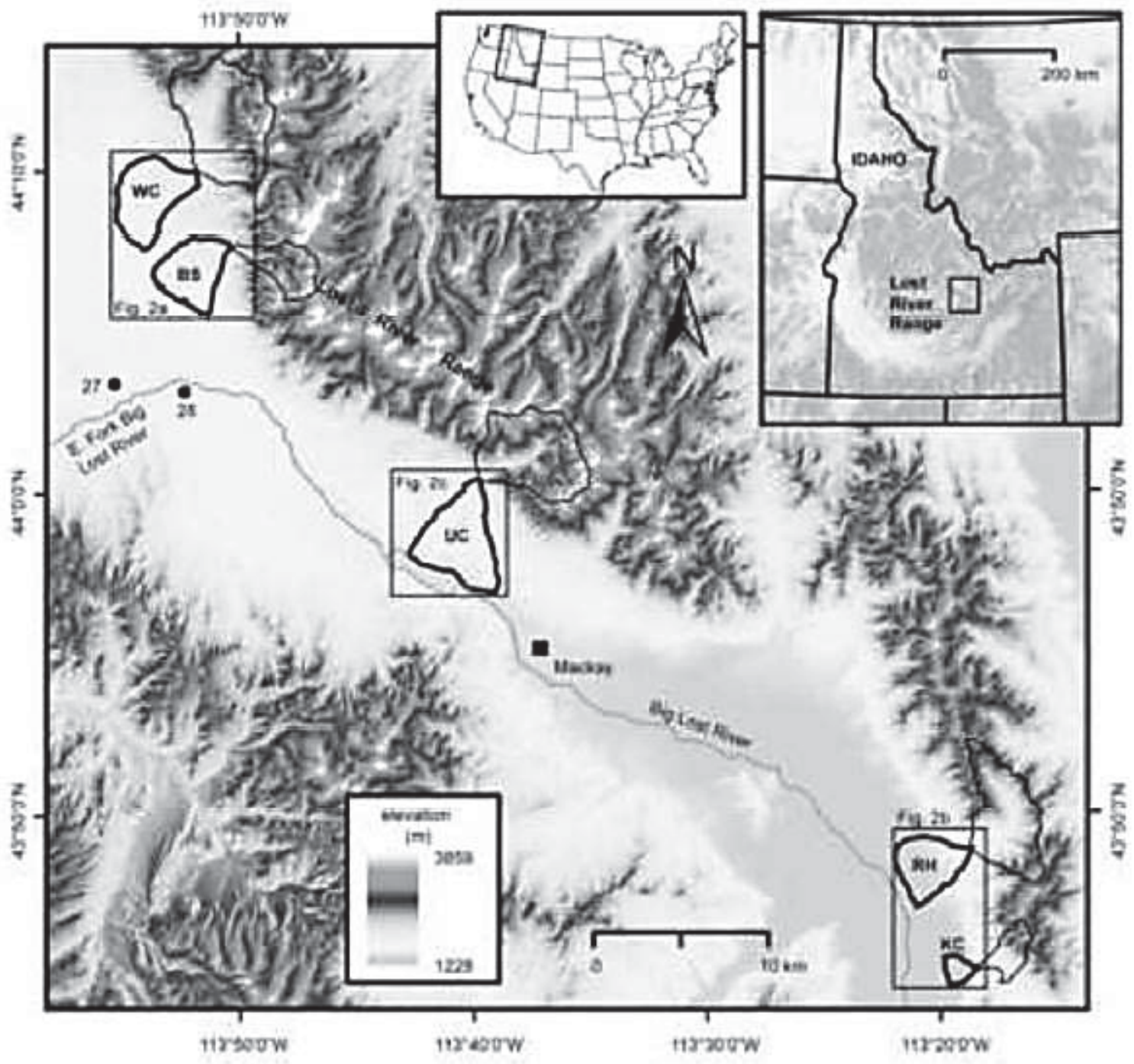

Figure 1 

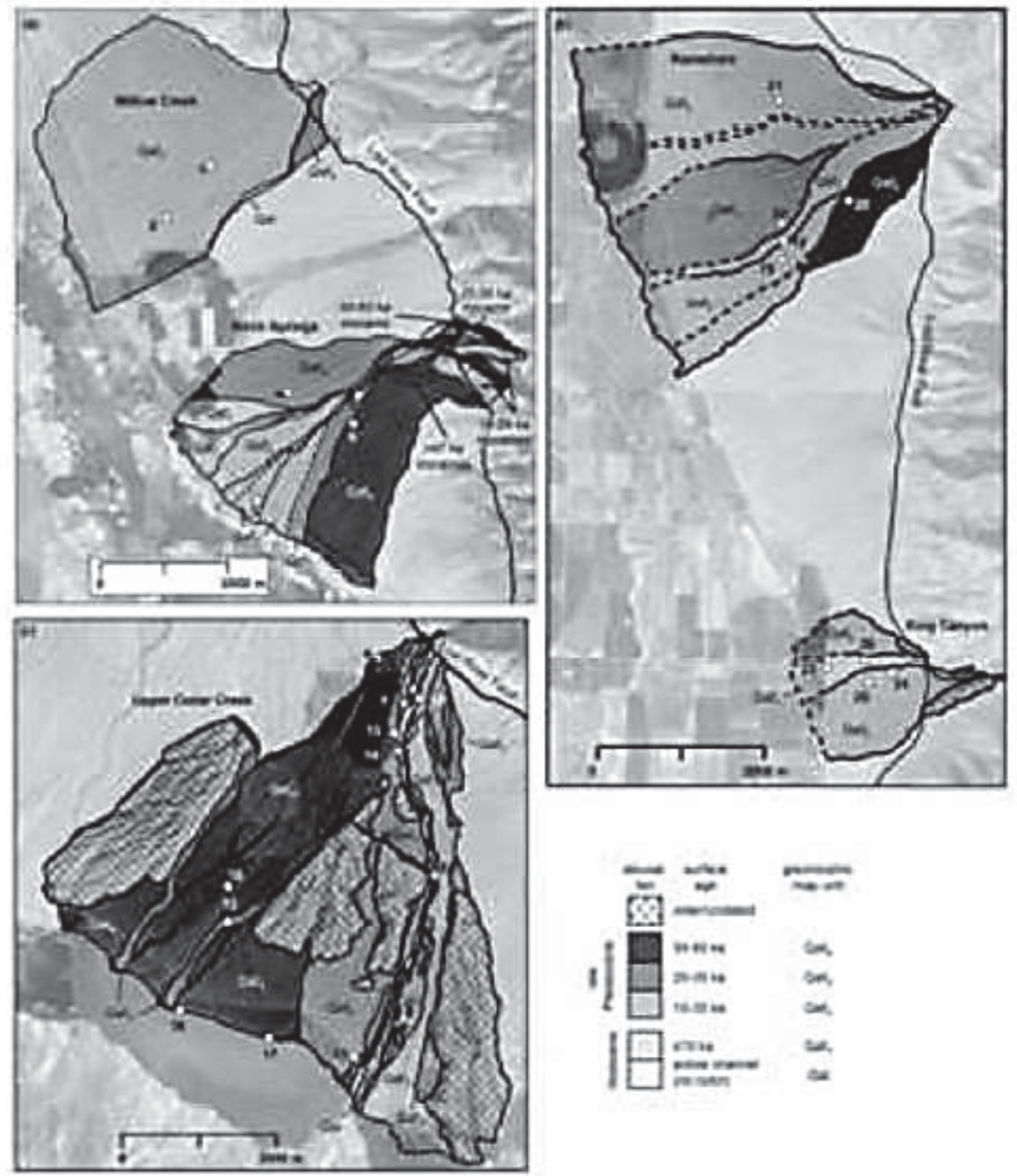

Figure 2 


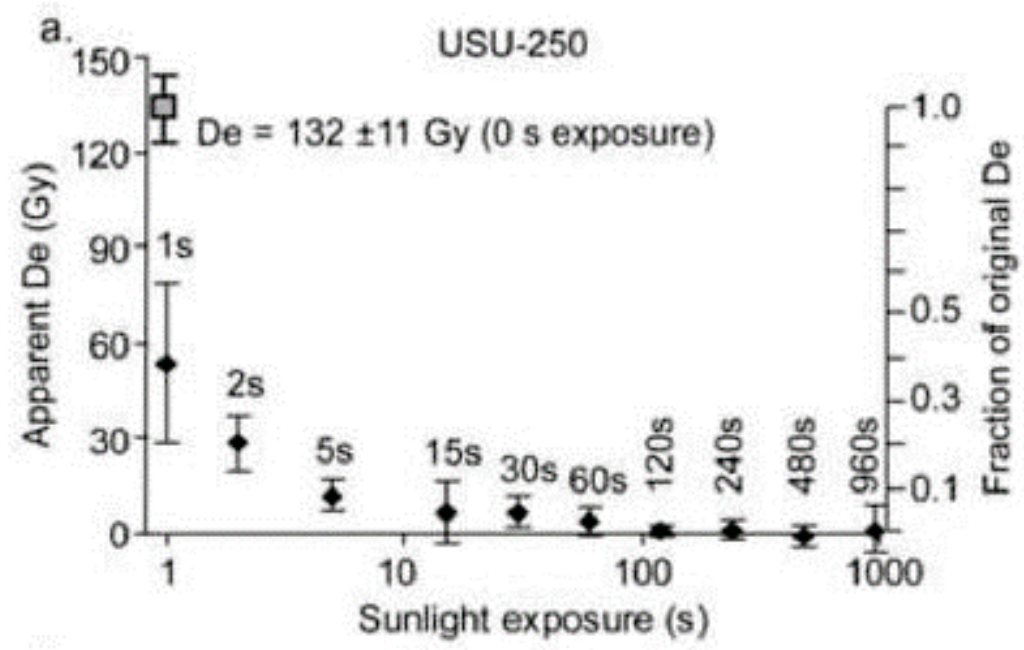

b.

- De with $>60$ s sunlight exposure

- De with $\leq 60$ s sunlight exposure

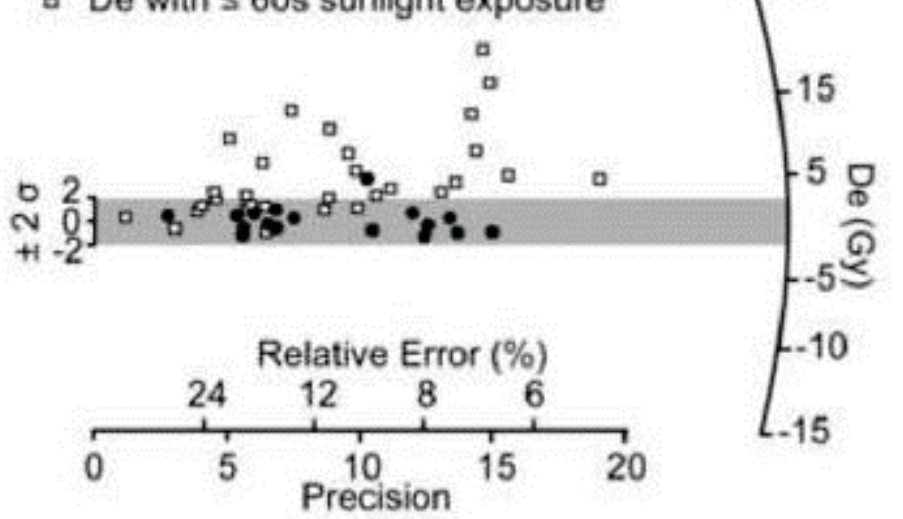

c.

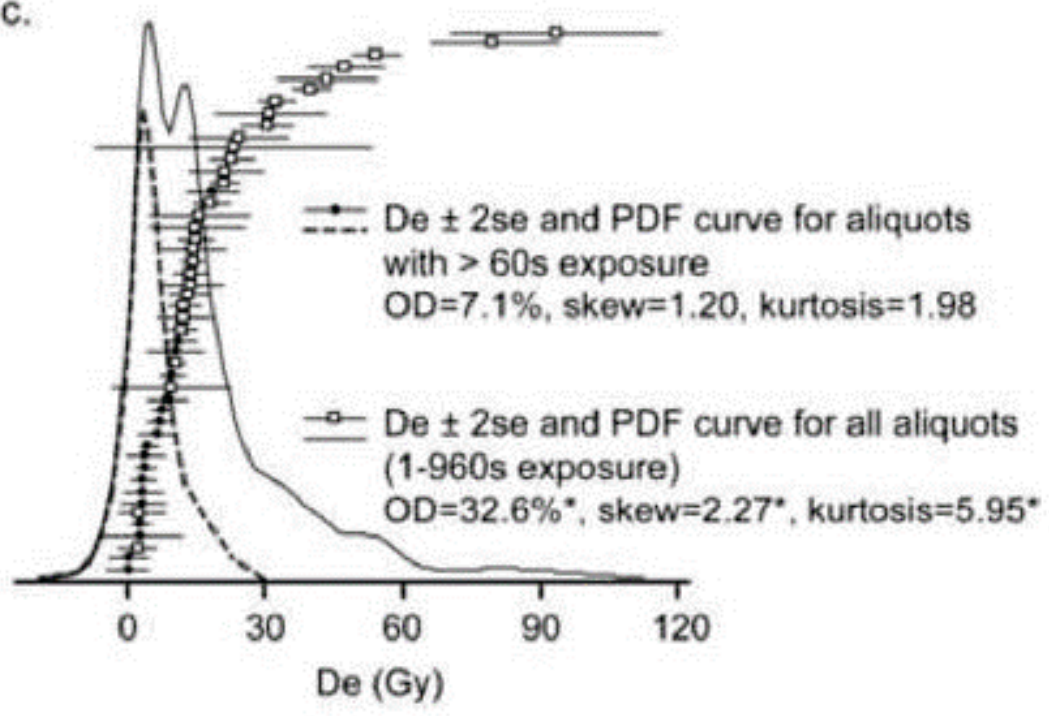

Figure 3 


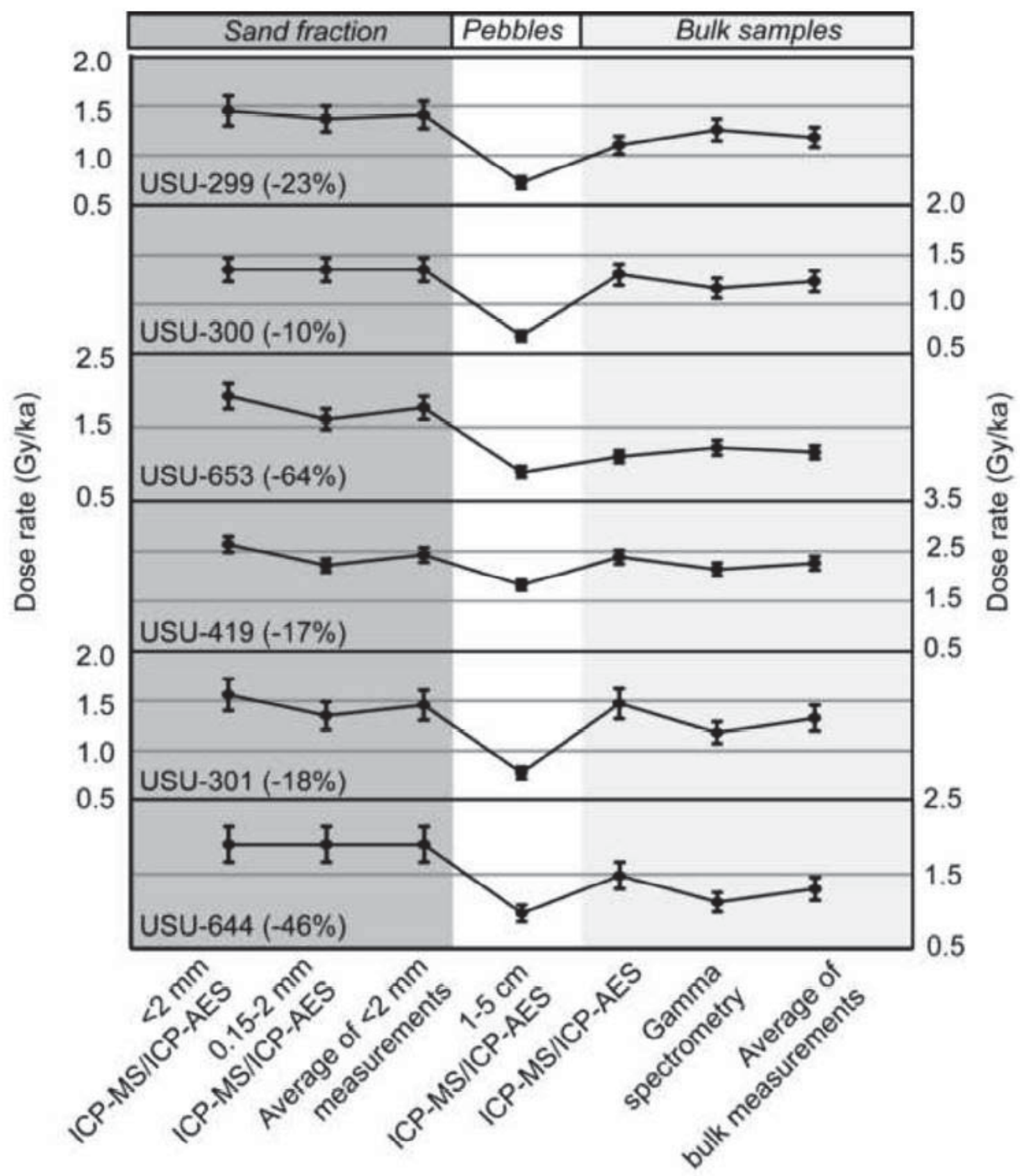

Figure 4 


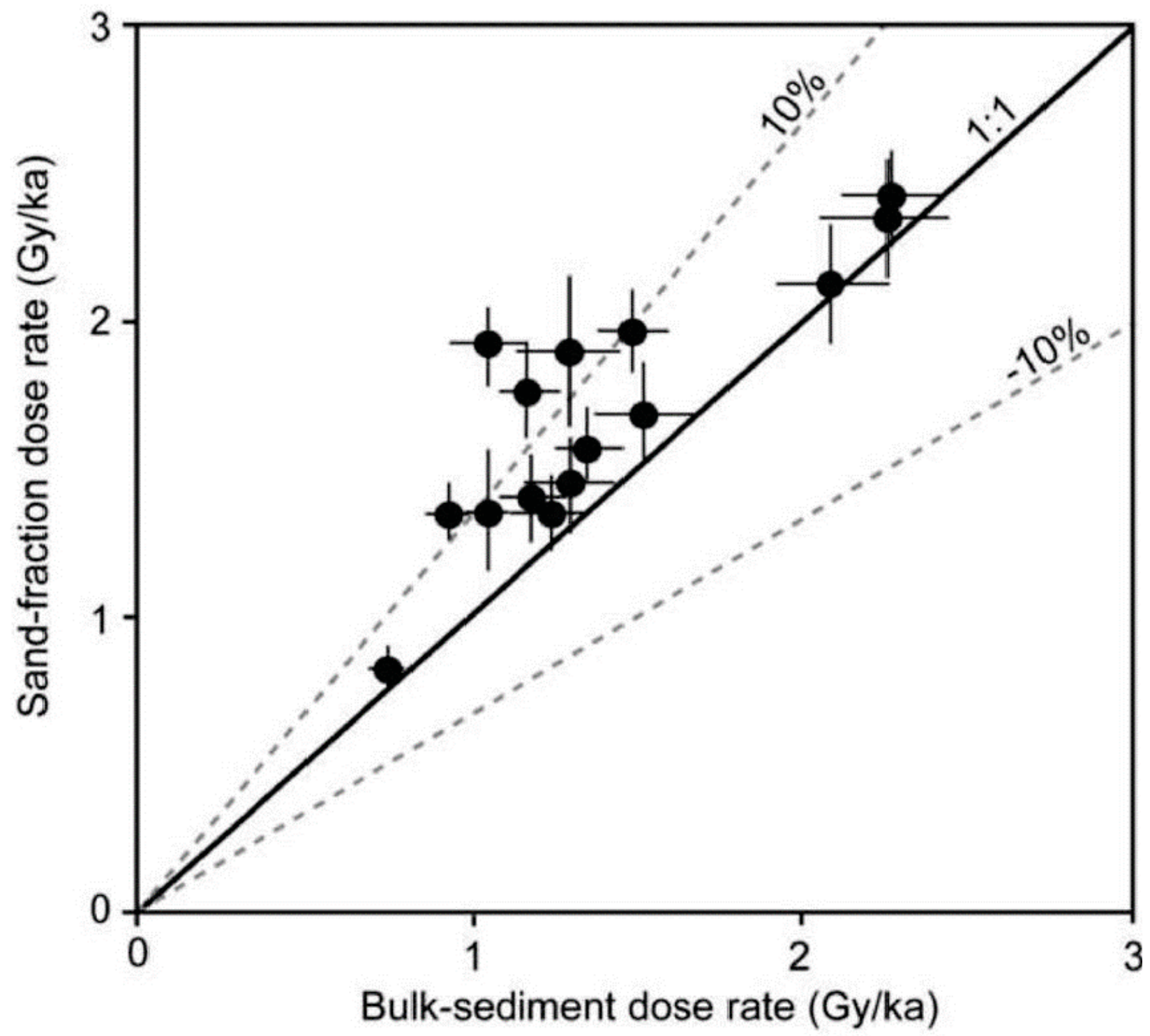

Figure 5 
This is an author-produced, peer-reviewed version of this article. The final, definitive version of this document can be found online at Quaternary Geochronology, published by Elsevier. Copyright restrictions may apply. doi: 10.1016/j.quageo.2014.03.004

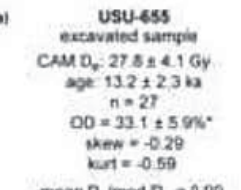

mean $D_{2} /$ med $D_{0}=0.90$

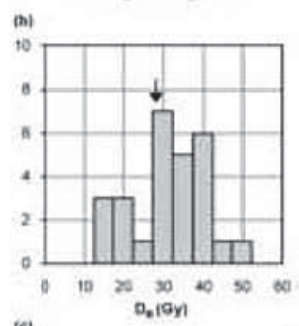

(e)
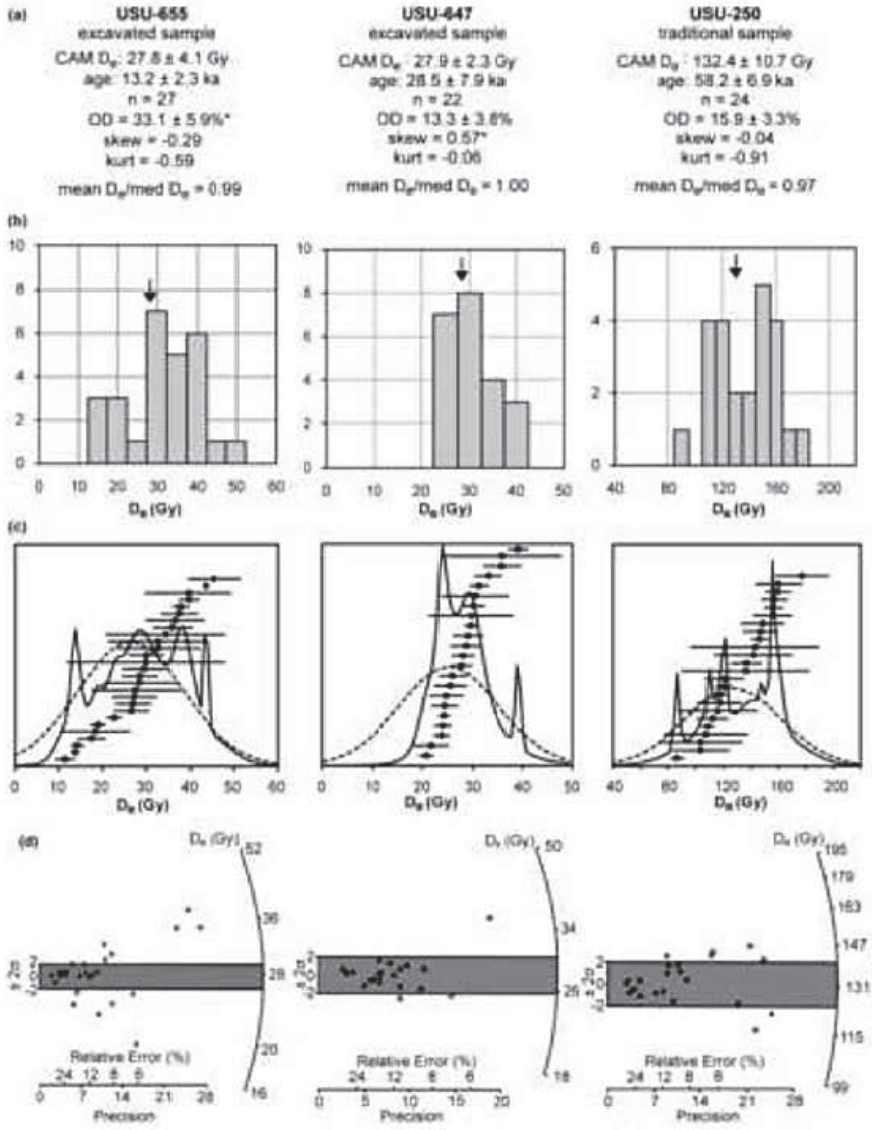

crup 13240.5070

excavined sampie.

22.230

age $2 \pi 5+7$
$n=22$

$00=133 \pm 30 \%$

sinew $=0.57$

$\operatorname{man} \mathrm{D}_{2}=\operatorname{med} \mathrm{D}_{8}=100$

age

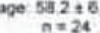

$O D=15.9+33 \%$

kun $=-0.91$

mean D,med $D_{0}=0.97$
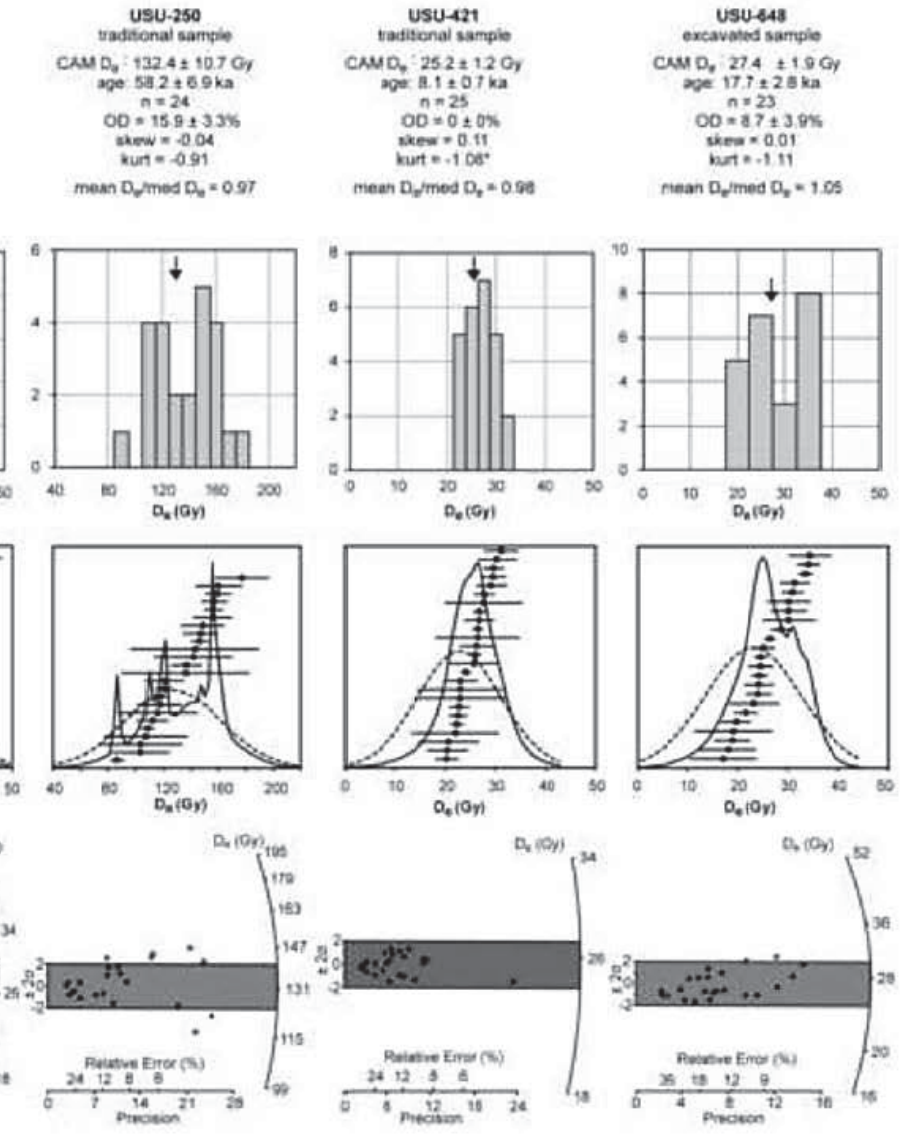

Figure 6 
This is an author-produced, peer-reviewed version of this article. The final, definitive version of this document can be found online at Quaternary Geochronology, published by Elsevier. Copyright restrictions may apply. doi: 10.1016/j.quageo.2014.03.004
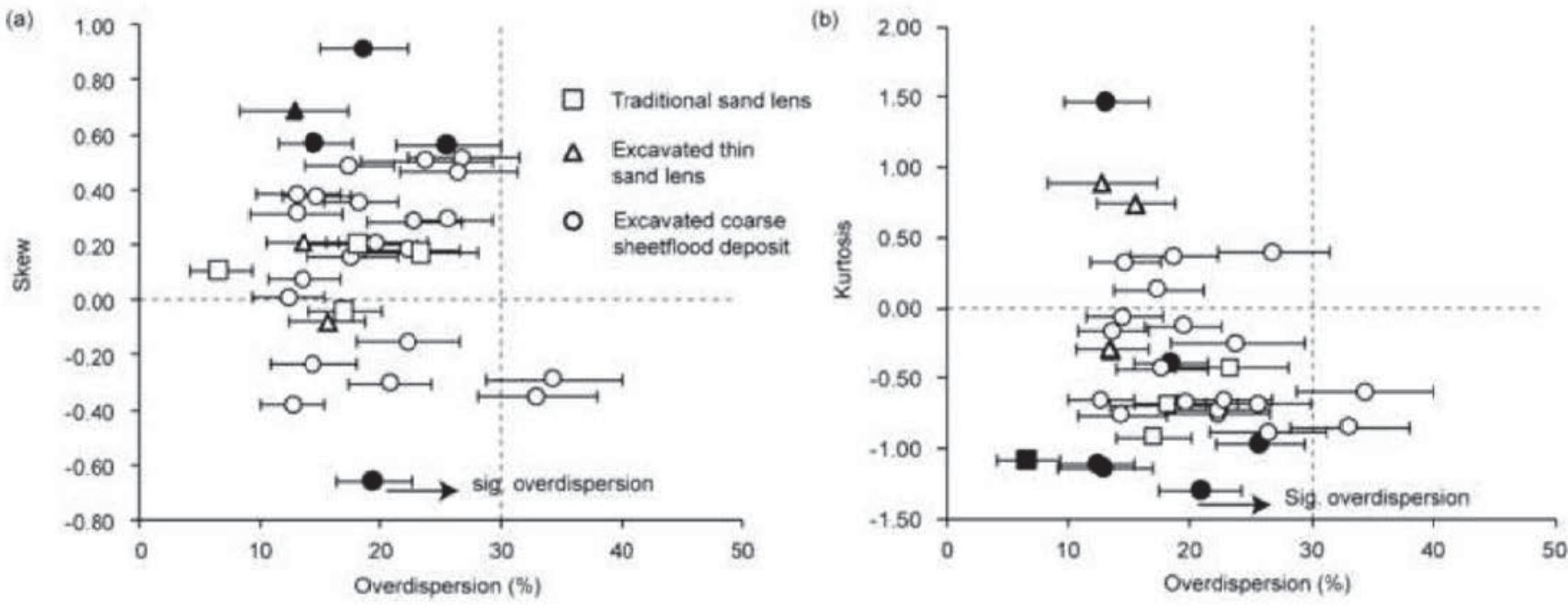

Figure 7 
This is an author-produced, peer-reviewed version of this article. The final, definitive version of this document can be found online at Quaternary Geochronology, published by Elsevier. Copyright restrictions may apply. doi: 10.1016/j.quageo.2014.03.004

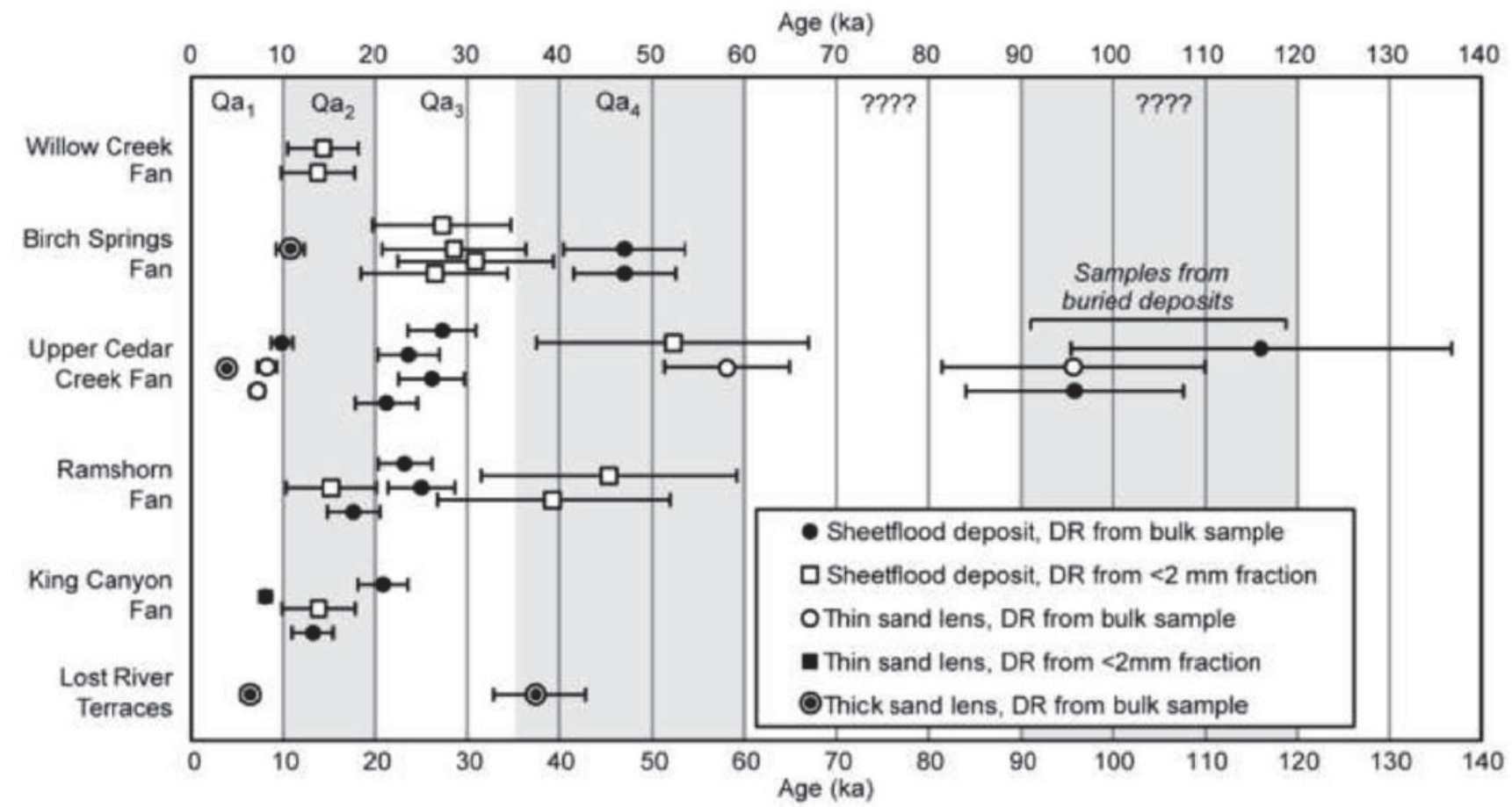

Figure 8 


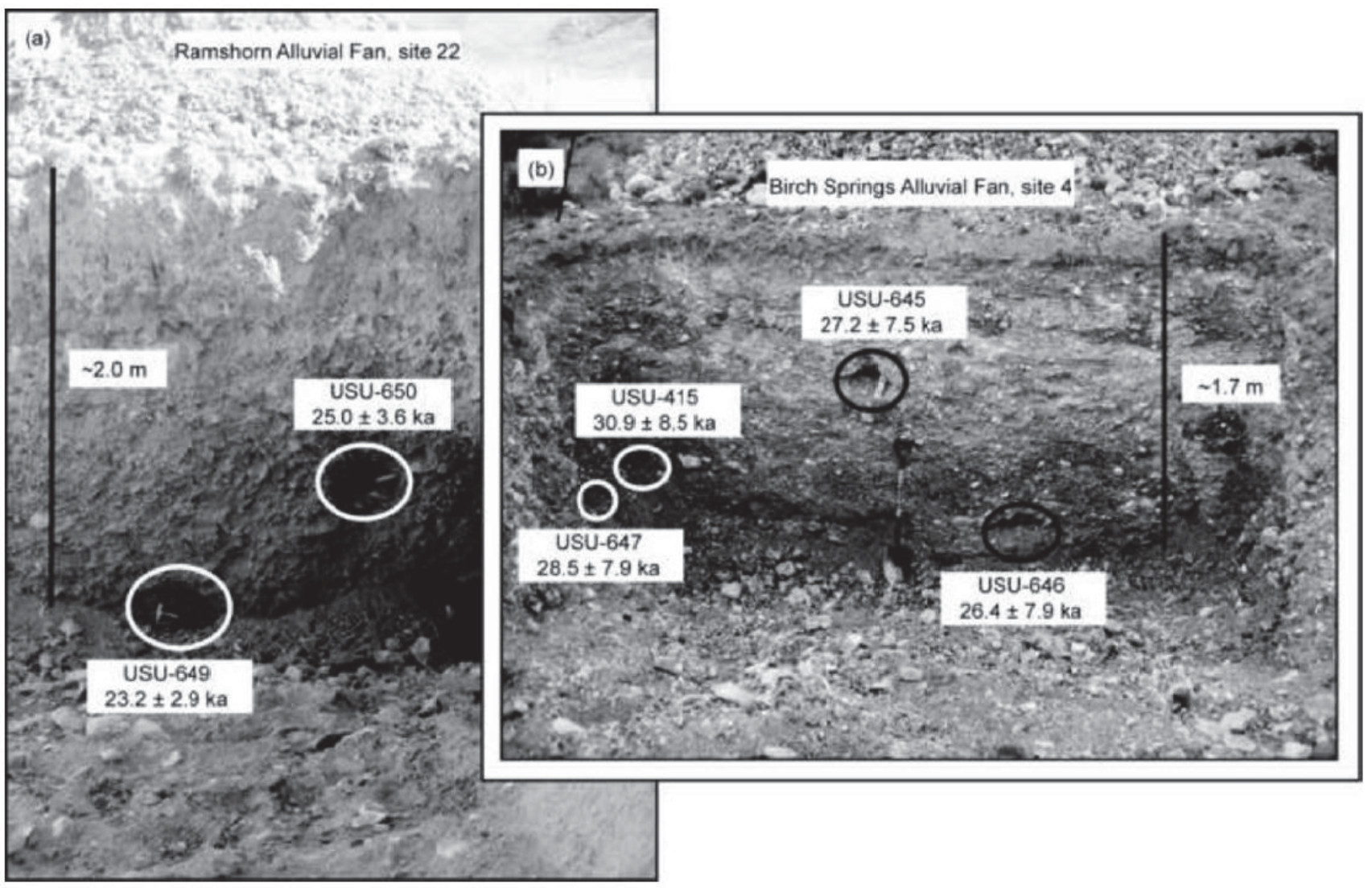

Figure 9 


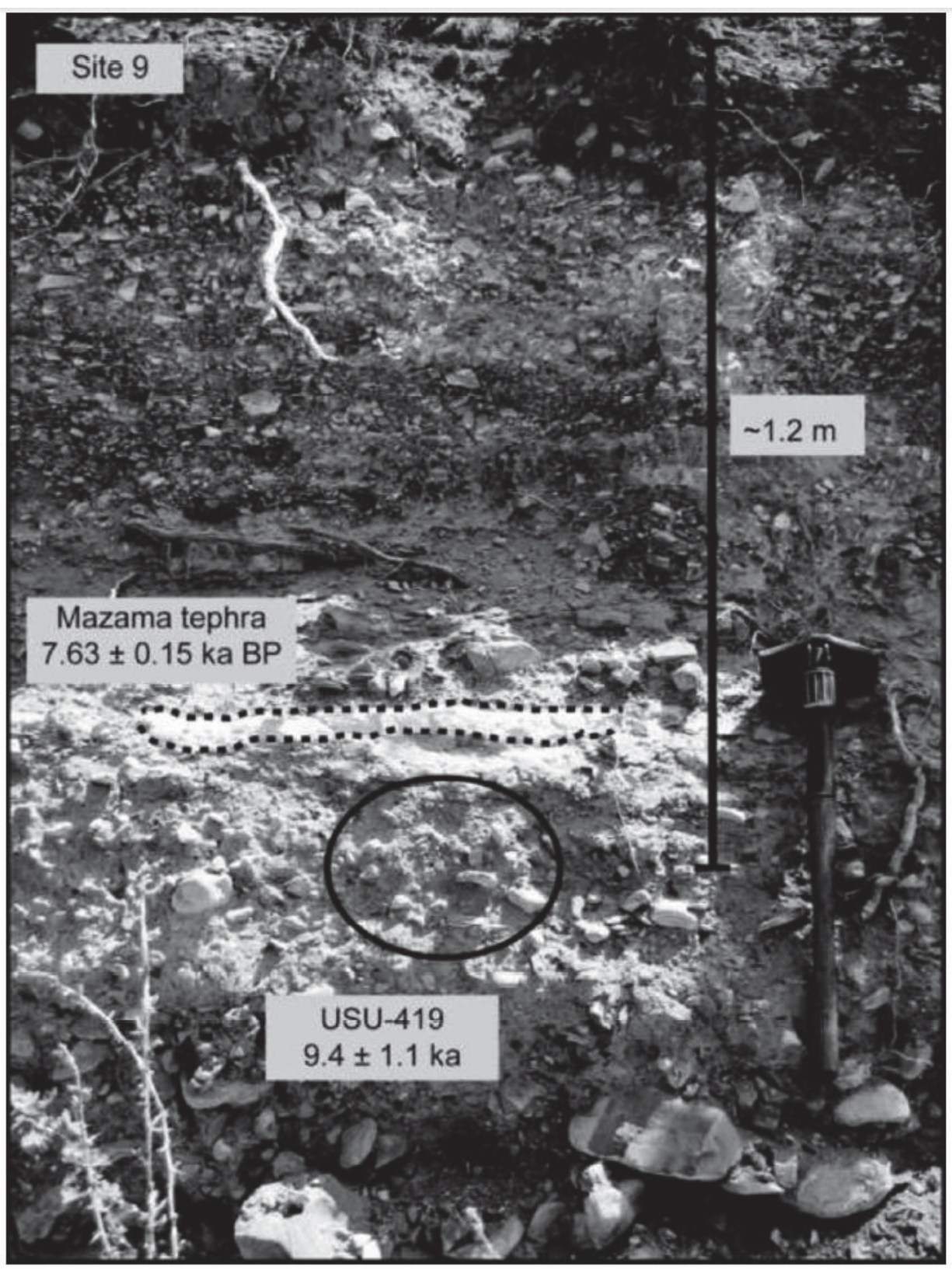

Figure 10 


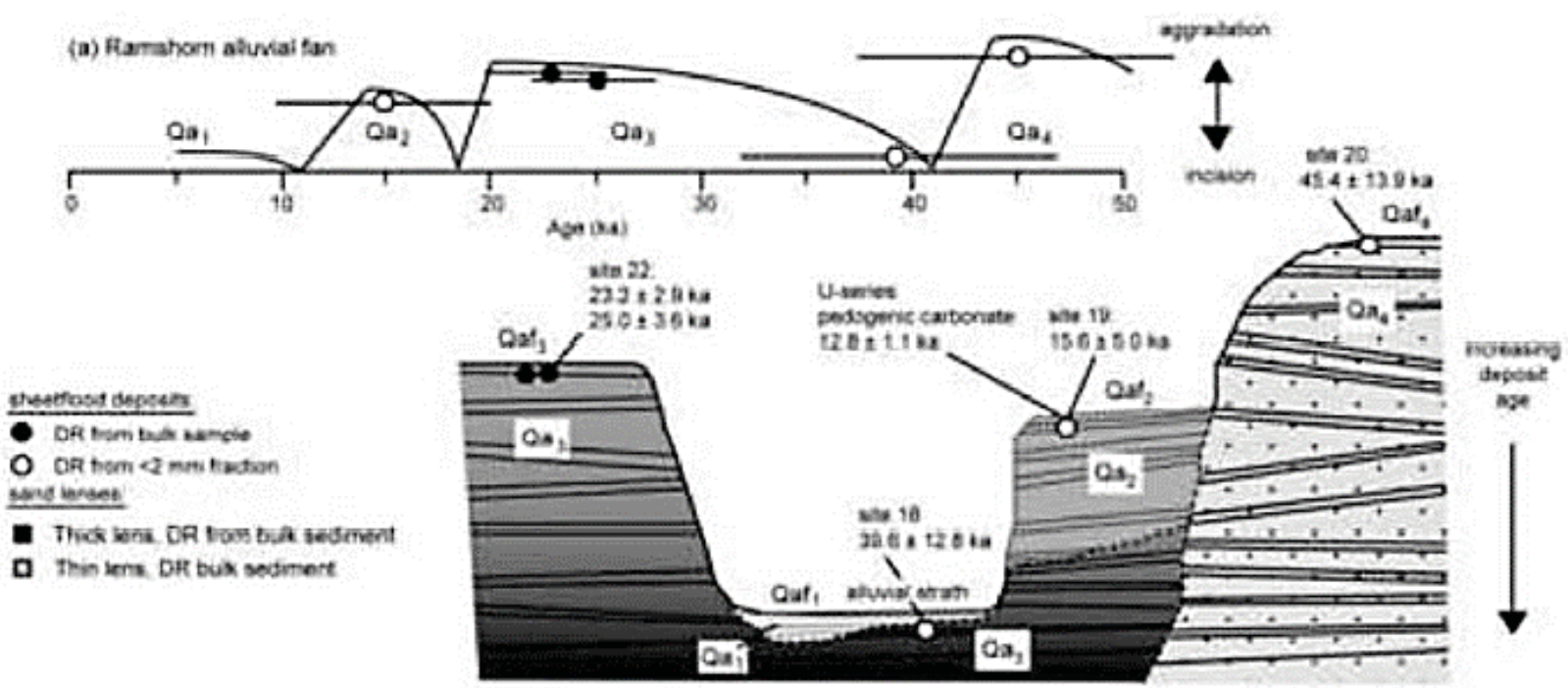

(b) Breth Spengi mituviaitan
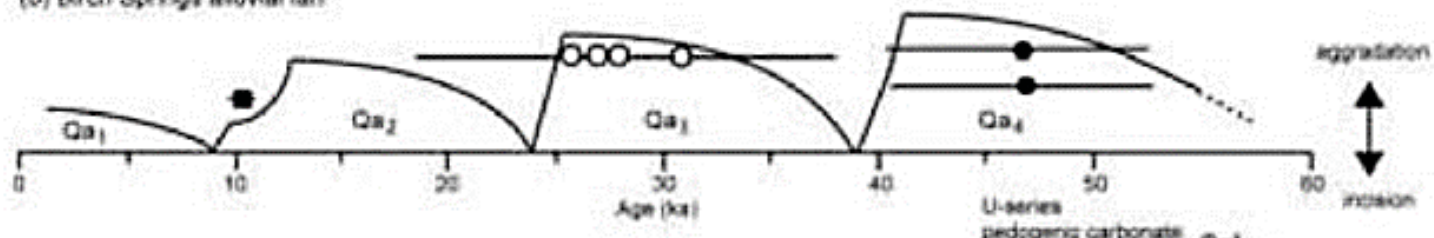

U-series pedsomes carbonats oats
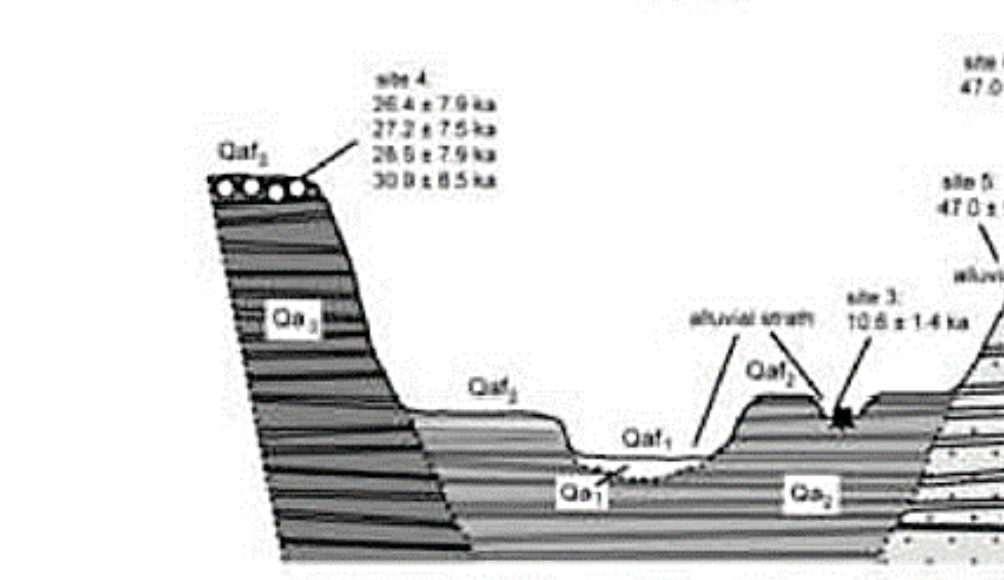

(c) Kong Carryon alluviai fan
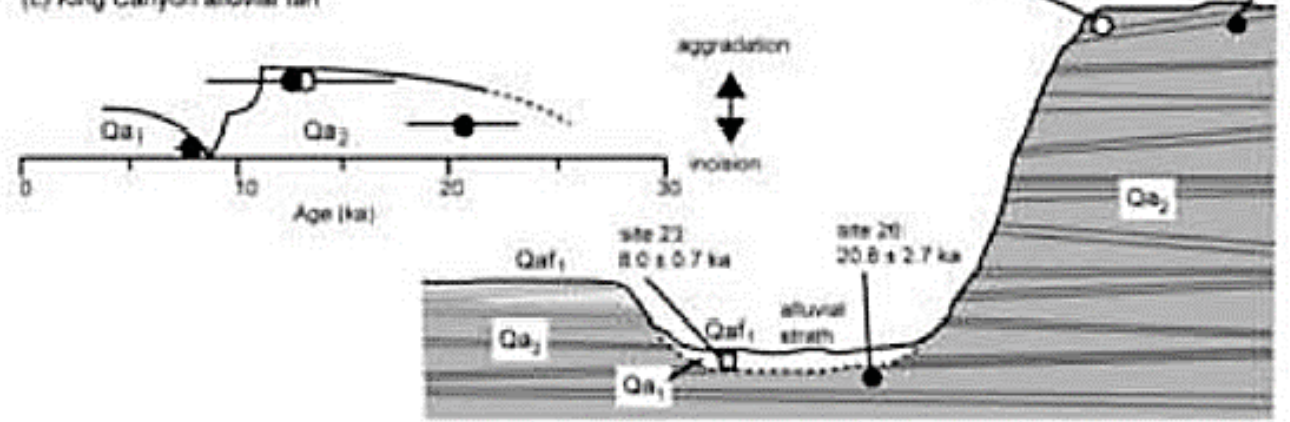

1423

$62 \div 230$

$09240 \mathrm{ko} \mathrm{Oot}$
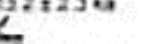
This is an author-produced, peer-reviewed version of this article. The final, definitive version of this document can be found online at Quaternary Geochronology, published by Elsevier. Copyright restrictions may apply. doi: 10.1016/j.quageo.2014.03.004

Table 1.

\begin{tabular}{|c|c|c|c|c|c|c|c|c|c|c|c|}
\hline $\begin{array}{l}\text { Alluvial } \\
\text { fan }\end{array}$ & & $\begin{array}{l}\text { Site } \\
\text { No. }\end{array}$ & USU Lab No. & $\begin{array}{c}\text { Burial } \\
\text { depth } \\
(\mathrm{m})\end{array}$ & $\begin{array}{c}\text { In Situ } \\
\mathrm{H}_{2} \mathrm{O} \\
\text { (wt \%) }\end{array}$ & $\begin{array}{c}u^{j} \\
(p p m)\end{array}$ & $\begin{array}{c}\mathrm{Th}^{\mathrm{j}} \\
(\mathrm{ppm})\end{array}$ & $\begin{array}{c}K^{j} \\
(\%)\end{array}$ & $\begin{array}{c}\mathrm{Rb}^{\mathrm{j}} \\
(\mathrm{ppm})\end{array}$ & $\begin{array}{l}\text { Cosmic } \\
\pm 10 \% \\
\text { (Gy/ka) }\end{array}$ & $\begin{array}{c}\text { Dose Rate } \\
\text { (Gy/ka) }^{\text {k }}\end{array}$ \\
\hline \multirow{2}{*}{\multicolumn{2}{|c|}{$\begin{array}{l}\text { Willow } \\
\text { Creek } \\
\text { (WC) }\end{array}$}} & 1 & USU- $412^{\mathrm{a}, \mathrm{\theta}}$ & 1.4 & 2.1 & $4.0 \pm 0.3$ & $4.9 \pm 0.4$ & $1.27 \pm 0.04$ & $61.1 \pm 3.4$ & 0.25 & $2.72 \pm 0.70$ \\
\hline & & 2 & USU- $413^{a, 0}$ & 2.0 & 4.0 & $3.8 \pm 0.3$ & $4.9 \pm 0.4$ & $1.33 \pm 0.04$ & $64.8 \pm 4.9$ & 0.24 & $2.70 \pm 0.69$ \\
\hline \multirow{7}{*}{\multicolumn{2}{|c|}{$\begin{array}{l}\text { Birch } \\
\text { Springs } \\
\text { (BS) }\end{array}$}} & 3 & USU-414 ${ }^{b}$ & 1.5 & 9.1 & $1.2 \pm 0.1$ & $2.4 \pm 0.2$ & $0.56 \pm 0.01$ & $23.2 \pm 0.9$ & 0.25 & $1.16 \pm 0.05$ \\
\hline & & 4 & USU- $415^{\mathrm{a}, \theta}$ & 1.5 & 0.5 & $1.2 \pm 0.1$ & $1.6 \pm 0.2$ & $0.44 \pm 0.06$ & $17.6 \pm 1.2$ & 0.25 & $1.02 \pm 0.27$ \\
\hline & & 4 & USU-645 ${ }^{a, e}$ & 1.2 & 0.5 & $1.2 \pm 0.1$ & $1.5 \pm 0.2$ & $0.40 \pm 0.04$ & $17.9 \pm 2.1$ & 0.26 & $0.99 \pm 0.26$ \\
\hline & & 4 & USU-646 ${ }^{\mathrm{a}, \mathrm{e}}$ & 1.5 & 1.5 & $1.2 \pm 0.2$ & $1.5 \pm 0.4$ & $0.41 \pm 0.09$ & $16.3 \pm 3.1$ & 0.25 & $0.98 \pm 0.26$ \\
\hline & & 4 & USU- $647^{\mathrm{a}, \mathrm{e}}$ & 1.5 & 1.2 & $1.2 \pm 0.1$ & $1.5 \pm 0.2$ & $0.40 \pm 0.05$ & $17.0 \pm 2.2$ & 0.25 & $0.98 \pm 0.25$ \\
\hline & & 5 & USU-703 $3^{a, f}$ & 1.8 & 2.4 & $1.1 \pm 0.1$ & $1.3+0.2$ & $0.40 \pm 0.02$ & $15.8 \pm 0.6$ & 0.25 & $0.94 \pm 0.06$ \\
\hline & & 6 & USU-704, & 1.7 & 1.8 & $0.8 \pm 0.1$ & $1.1 \pm 0.2$ & $0.31 \pm 0.01$ & $10.5 \pm 0.4$ & 0.25 & $0.76 \pm 0.05$ \\
\hline \multirow{13}{*}{\multicolumn{2}{|c|}{$\begin{array}{l}\text { Upper } \\
\text { Cedar } \\
\text { Creek } \\
\text { (UC) }\end{array}$}} & 7 & USU- $251^{b}$ & 1.9 & 2.6 & $2.0 \pm 0.1$ & $12.3 \pm 1.1$ & $2.39 \pm 0.06$ & $110.5 \pm 4.4$ & 0.24 & $3.93 \pm 0.17$ \\
\hline & & 8 & USU-417 & 5.0 & 1.9 & $3.1 \pm 0.2$ & $4.2 \pm 0.4$ & $1.10 \pm 0.03$ & $51.6 \pm 2.1$ & 0.16 & $2.25 \pm 0.10$ \\
\hline & & 9 & USU- $419^{a, f}$ & 1.2 & 3.0 & $2.8 \pm 0.2$ & $5.2 \pm 1.3$ & $1.06 \pm 0.05$ & $55.1 \pm 2.2$ & 0.27 & $2.31 \pm 0.14$ \\
\hline & & 10 & USU- $652^{c, f}$ & 3.2 & 3.9 & $3.0 \pm 0.2$ & $4.5 \pm 0.5$ & $1.12 \pm 0.20$ & $53.3 \pm 4.3$ & 0.21 & $2.28 \pm 0.19$ \\
\hline & & 11 & USU-299 ${ }^{\mathrm{a}, \mathrm{t}^{\prime}}$ & 2.3 & 3.2 & $2.5 \pm 0.2$ & $1.6 \pm 0.4$ & $0.35 \pm 0.08$ & $16.1 \pm 0.6$ & 0.22 & $1.20 \pm 0.10$ \\
\hline & & 11 & USU-300 & 3.2 & 2.4 & $2.4 \pm 0.2$ & $1,9 \pm 0,3$ & $0,42 \pm 0.08$ & $22.7 \pm 5.7$ & 0.19 & $1.25 \pm 0.10$ \\
\hline & & 12 & USU- $653^{a, f}$ & 1.6 & 1.2 & $2.1 \pm 0.2$ & $1.7 \pm 0.4$ & $0.38 \pm 0.06$ & $17.5 \pm 0.7$ & 0.24 & $1.18 \pm 0.09$ \\
\hline & & 13 & USU-301 $1^{a, f}$ & 1.9 & 5.6 & $2.7 \pm 0.3$ & $1.8 \pm 0.4$ & $0.40 \pm 0.12$ & $24.8 \pm 1.0$ & 0.24 & $1.32 \pm 0.13$ \\
\hline & & 14 & USU-416 ${ }^{a, 1,9}$ & 15.0 & 1.8 & $2.6 \pm 0.6$ & $1.6 \pm 0.5$ & $0.34 \pm 0.09$ & $13.4 \pm 0.5$ & 0.06 & $1.06 \pm 0.15$ \\
\hline & & 14 & USU-302 $2^{a, f}$ & 20.0 & 4.4 & $2.6 \pm 0.2$ & $2.8 \pm 0.3$ & $0.62+0.04$ & $29.4 \pm 1.2$ & 0.04 & $1.37 \pm 0.10$ \\
\hline & & 15 & USU $-420^{a, \theta}$ & 1.7 & 2.2 & $3.3 \pm 0.4$ & $3.4 \pm 0.8$ & $0.85 \pm 0.19$ & $41.8 \pm 7.9$ & 0.24 & $1.95 \pm 0.53$ \\
\hline & & 16 & USU $-250^{b}$ & 1.9 to $18^{h}$ & 0.4 & $3.2 \pm 0.2$ & $4.9 \pm 0.4$ & $1.24 \pm 0.03$ & $63.2 \pm 2.5$ & $0.23 \& 0.05$ & $2.28 \pm 0.16$ \\
\hline & & 17 & USU- $644^{c, f}$ & 3.5 & 0.5 & $2.4 \pm 0.4$ & $2.1 \pm 0.8$ & $0.51 \pm 0.13$ & $30.8 \pm 1.2$ & 0.18 & $1,31 \pm 0,15$ \\
\hline \multirow{6}{*}{\multicolumn{2}{|c|}{$\begin{array}{l}\text { Ramshorn } \\
\text { (RH) }\end{array}$}} & 18 & USU-305 & 1.9 & 6.5 & $2.1 \pm 0.1$ & $1.7 \pm 1.0$ & $0.43 \pm 0.25$ & $17.8 \pm 10.5$ & 0.23 & $1.17 \pm 0.36$ \\
\hline & & 19 & USU-306 & 2.0 & 6.0 & $2.5 \pm 0.3$ & $2.2 \pm 1.1$ & $0.55 \pm 0.29$ & $22.6 \pm 12.2$ & 0.23 & $1.43 \pm 0.43$ \\
\hline & & 20 & USU-307 & 1.8 & 3.3 & $2.1 \pm 0.2$ & $1.4 \pm 0.6$ & $0.31 \pm 0.11$ & $12.5 \pm 4.4$ & 0.23 & $1.07 \pm 0.29$ \\
\hline & & 21 & USU-648 $8^{a, f}$ & 1.6 & 3.2 & $2.0 \pm 0.7$ & $3.2 \pm 1.1$ & $0.67 \pm 0.11$ & $42.4 \pm 1.7$ & 0.24 & $1.55 \pm 0.21$ \\
\hline & & 22 & USU- $649^{a, f}$ & 2.0 & 7.2 & $2.2 \pm 0.2$ & $1.7 \pm 0.2$ & $0.43 \pm 0.01$ & $18.9 \pm 0.8$ & 0.22 & $1.21 \pm 0.08$ \\
\hline & & 22 & USU- $650^{\mathrm{a},{ }^{\prime}}$ & 1.6 & 3.0 & $1.9 \pm 0.1$ & $1.4 \pm 0.6$ & $0.34 \pm 0.11$ & $18.5 \pm 0.7$ & 0.24 & $1.07 \pm 0.11$ \\
\hline \multirow{4}{*}{\multicolumn{2}{|c|}{$\begin{array}{l}\text { King } \\
\text { Canyon } \\
\text { (KC) }\end{array}$}} & 23 & USU $-421^{b}$ & 1.0 & 0.7 & $3.2 \pm 0.2$ & $9.7 \pm 0.9$ & $1.53 \pm 0.04$ & $67.3 \pm 2.7$ & 0.25 & $3.13 \pm 0.14$ \\
\hline & & 24 & USU-422 $2^{\mathrm{a}, \mathrm{e}}$ & 1.6 & 3.3 & $3.1 \pm 0.2$ & $4.2 \pm 1.6$ & $0.90 \pm 0.23$ & $38.8 \pm 9.3$ & 0.24 & $2.07 \pm 0.57$ \\
\hline & & 25 & USU-655 $5^{\mathrm{a}, \mathrm{f}}$ & 1.9 & 2.0 & $2.8 \pm 0.4$ & $4.1 \pm 0.4$ & $0.99 \pm 0.09$ & $38.7 \pm 1.5$ & 0.23 & $2.11 \pm 0.16$ \\
\hline & & 26 & USU- $656^{a, f}$ & 2.0 & 2.4 & $2.1 \pm 0.1$ & $3.0 \pm 0.3$ & $0.66 \pm 0.02$ & $29.1 \pm 1.2$ & 0.22 & $1.51 \pm 0.10$ \\
\hline \multirow{2}{*}{\multicolumn{2}{|c|}{$\begin{array}{l}\text { E. Fork Big } \\
\text { Lost River } \\
\text { Terraces }\end{array}$}} & 27 & USU- $304^{b}$ & 13.4 & 6.0 & $3.7 \pm 0.3$ & $12.0 \pm 1.1$ & $2.22 \pm 0.06$ & $98.1 \pm 3.9$ & 0.07 & $3.74 \pm 0.27$ \\
\hline & & 28 & USU-651 ${ }^{\mathrm{b}}$ & 1.1 & 2.2 & $3.9 \pm 0.3$ & $13.5 \pm 1.2$ & $2.54 \pm 0.06$ & $115.0 \pm 4.6$ & 0.26 & $4.60 \pm 0.21$ \\
\hline \multicolumn{12}{|c|}{ a Alluvial fan sheetflood deposits sampled at night or under tarps. } \\
\hline b $\mathrm{Tr}$ & \multicolumn{11}{|c|}{ Traditional sample from large sand lens. } \\
\hline \multicolumn{12}{|c|}{ c Traditional sample from thin sand lens. } \\
\hline \multicolumn{12}{|c|}{ d Thin sand lens sampled at night. } \\
\hline \multicolumn{12}{|c|}{ e Dose rate based on average values from $<2 \mathrm{~mm}$ grain size fraction and $\sim 125-2000 \mu \mathrm{m}$ grain size fraction. $25 \%$ uncertainty added to dose rate uncertainty. } \\
\hline \multicolumn{12}{|c|}{ f Dose rate based on bulk sediment samples with all grain sizes in correct proportion. } \\
\hline h Bt & \multicolumn{11}{|c|}{ Burial depth modeled due to changes over time. } \\
\hline \multirow{2}{*}{1} & \multicolumn{11}{|c|}{ If measured $\mathrm{H}_{2} \mathrm{O}$ content $<3 \%, \mathrm{H}_{2} \mathrm{O}$ content modeled as $3 \pm 3 \%$ for the Holocene and $8 \pm 8 \%$ for the late Pleistocene. } \\
\hline & \multicolumn{11}{|c|}{ If measured $\mathrm{H}_{2} \mathrm{O}$ content $>3 \%$, measured value used. } \\
\hline j Ur & \multicolumn{11}{|c|}{$\begin{array}{l}\text { Uncertainty on ICP-MS measurements follows Goble } \\
\text { different grain size fractions. } \\
\text { Dose rate conversion following Guerin et al. (2011) }\end{array}$} \\
\hline
\end{tabular}


This is an author-produced, peer-reviewed version of this article. The final, definitive version of this document can be found online at Quaternary Geochronology, published by Elsevier. Copyright restrictions may apply. doi: 10.1016/j.quageo.2014.03.004

Table 2.

\begin{tabular}{|c|c|c|c|c|c|c|c|c|c|c|c|c|c|}
\hline Sample type & $\begin{array}{l}\text { Site } \\
\text { no. }\end{array}$ & Fan & $\begin{array}{c}\text { USU Lab } \\
\text { no. }\end{array}$ & $\begin{array}{l}\text { No. of } \\
\text { aliquots }\end{array}$ & $\begin{array}{c}\text { Mean } \\
D_{e}\end{array}$ & $\begin{array}{c}\text { Median } \\
D_{e}\end{array}$ & $\begin{array}{c}\text { Mean } \mathrm{D}_{\mathrm{e}} \\
\text { /median } \mathrm{D}_{\mathrm{e}}\end{array}$ & Skew & Kurtosis & $\begin{array}{c}\text { Over- } \\
\text { dispersion }\end{array}$ & $\begin{array}{c}\text { Dose rate } \\
\text { (Gy/ka) }\end{array}$ & $\begin{array}{l}D_{e}(G y) \\
\pm 2 \sigma \text { se }\end{array}$ & $\begin{array}{c}\text { Optical age (ka) } \\
\pm 2 \sigma \text { se }\end{array}$ \\
\hline \multirow{4}{*}{$\begin{array}{l}\text { Traditional } \\
\text { tube sample } \\
\text { from thick } \\
\text { sand lens }\end{array}$} & 3 & BS & USU-414 & 26 & 12.3 & 11.7 & 1.05 & 0.20 & -0.68 & $18 \pm 6$ & $1.16 \pm 0.05$ & $12.2 \pm 1.4$ & $10.6 \pm 1.4$ \\
\hline & 7 & UC & USU-251 & 25 & 15.8 & 15.5 & 1.02 & 0.17 & -0.42 & $21 \pm 5$ & $3.93 \pm 0.17$ & $15.5 \pm 1.8$ & $4.0 \pm 0.5$ \\
\hline & 27 & EFBL & USU-304 & 33 & 143.2 & 145.5 & 0.99 & 0.25 & -0.49 & $27 \pm 4$ & $3.74 \pm 0.27$ & $142.4 \pm 15.1$ & $38.0 \pm 5.3$ \\
\hline & 28 & EFBL & USU-651 & 23 & 29.9 & 28.4 & 1.05 & 0.45 & $-1.13^{\mathrm{a}}$ & $24 \pm 6$ & $4.60 \pm 0.21$ & $29.5 \pm 4.0$ & $6.4 \pm 1.0$ \\
\hline \multirow{2}{*}{$\begin{array}{l}\text { Traditional } \\
\text { sample from } \\
\text { thin sand } \\
\text { lens }\end{array}$} & 16 & UC & USU-250 & 24 & 132.6 & 136.5 & 0.97 & -0.04 & -0.91 & $16 \pm 3$ & $2.28 \pm 0.16$ & $132.4 \pm 10.7$ & $58.2 \pm 6.9$ \\
\hline & 23 & $\mathrm{KC}$ & USU-421 & 25 & 25.3 & 25.9 & 0.98 & 0.11 & $-1.08^{\mathrm{a}}$ & $0 \pm 0$ & $3.13 \pm 0.14$ & $25.2 \pm 1.2$ & $8.1 \pm 0.7$ \\
\hline \multirow{3}{*}{$\begin{array}{l}\text { Excavated } \\
\text { thin sand } \\
\text { lens }\end{array}$} & 8 & UC & USU-417 & 23 & 16.1 & 15.9 & 1.01 & 0.21 & -0.29 & $11 \pm 4$ & $2.25 \pm 0.10$ & $16.3 \pm 1.2$ & $7.2 \pm 0.7$ \\
\hline & 17 & UC & USU-644 & 21 & 129.6 & 124.1 & 1.04 & -0.08 & 0.75 & $12 \pm 4$ & $1.31 \pm 0.16$ & $125.7 \pm 9.7$ & $95.7 \pm 14.2$ \\
\hline & 10 & UC & USU-652 & 24 & 18.2 & 18.0 & 1.01 & $0.69^{\mathrm{a}}$ & 0.90 & $8 \pm 7$ & $2.28 \pm 0.19$ & $18.8 \pm 1.7$ & $8.3 \pm 1.1$ \\
\hline \multirow{25}{*}{$\begin{array}{l}\text { Excavated } \\
\text { sheetflood } \\
\text { deposit }\end{array}$} & 1 & WC & USU-412 & 24 & 37.0 & 37.3 & 0.99 & -0.38 & -0.65 & $9 \pm 3$ & $2.72 \pm 0.70^{b}$ & $39.1 \pm 2.4$ & $14.4 \pm 3.9$ \\
\hline & 2 & wc & USU-413 & 22 & 38.6 & 39.1 & 0.99 & 0.52 & 0.40 & $26 \pm 5$ & $2.70 \pm 0.69^{b}$ & $37.6 \pm 4.7$ & $13.9 \pm 4.0$ \\
\hline & 4 & BS & USU-415 & 23 & 31.7 & 31.8 & 1.00 & 0.38 & 0.33 & $13 \pm 3$ & $1.02 \pm 0.27^{b}$ & $31.6 \pm 2.3$ & $30.9 \pm 8.5$ \\
\hline & 4 & BS & USU-645 & 27 & 27.4 & 26.9 & 1.02 & 0.36 & -0.38 & $17 \pm 3$ & $0.99 \pm 0.26^{b}$ & $27.0 \pm 2.1$ & $27.2 \pm 7.5$ \\
\hline & 4 & BS & USU-646 & 24 & 26.7 & 24.7 & 1.08 & 0.46 & -0.88 & $25 \pm 5$ & $0.98+0.26^{b}$ & $26.0 \pm 3.2$ & $26.4 \pm 7.9$ \\
\hline & 4 & BS & USU-647 & 22 & 28.4 & 28.4 & 1.00 & $0.57^{\mathrm{a}}$ & -0.06 & $13 \pm 4$ & $0.98 \pm 0.25^{b}$ & $27.9 \pm 2.3$ & $28.5 \pm 7.9$ \\
\hline & 5 & BS & USU-703 & 24 & 44.8 & 46.4 & 0.96 & -0.65 & -0.13 & $18 \pm 3$ & $0.94 \pm 0.06$ & $44.4 \pm 3.7$ & $47.0 \pm 5.5$ \\
\hline & 6 & BS & USU-704 & 28 & 36.2 & 34.5 & 1.05 & $0.56^{\mathrm{a}}$ & -0.68 & $24 \pm 5$ & $0.76 \pm 0.05$ & $35.6 \pm 4.0$ & $47.0 \pm 6.5$ \\
\hline & 9 & UC & USU-419 & 24 & 21.7 & 21.0 & 1.04 & 0.49 & 0.14 & $15 \pm 4$ & $2.31 \pm 0.14$ & $21.6 \pm 1.9$ & $9.4 \pm 1.1$ \\
\hline & 11 & UC & USU-299 & 28 & 28.5 & 28.8 & 0.99 & -0.15 & -0.75 & $19 \pm 5$ & $1.20 \pm 0.10$ & $28.2 \pm 2.8$ & $23.6 \pm 3.3$ \\
\hline & 11 & UC & USU-300 & 24 & 33.9 & 31.9 & 1.06 & 0.21 & -0.67 & $16 \pm 5$ & $1.25 \pm 0.10$ & $34.12 \pm 3.3$ & $27.2 \pm 3.7$ \\
\hline & 12 & UC & USU-653 & 31 & 25.8 & 27.7 & 0.93 & -0.35 & -0.84 & $31 \pm 5$ & $1.18 \pm 0.09$ & $25.1 \pm 3.2$ & $21.2 \pm 3.3$ \\
\hline & 13 & UC & USU-301 & 26 & 32.4 & 33.0 & 0.98 & -0.23 & -0.76 & $12 \pm 4$ & $1.32 \pm 0.13$ & $34.8 \pm 2.9$ & $26.3 \pm 3.6$ \\
\hline & 14 & UC & USU-416 & 24 & 120.2 & 117.6 & 1.02 & 0.16 & -0.42 & $15 \pm 4$ & $1.06 \pm 0.15$ & $123.4 \pm 11.0$ & $116.1 \pm 20.6$ \\
\hline & 14 & UC & USU-302 & 22 & 132.1 & 126.4 & 1.05 & 0.32 & $-1.14^{\mathrm{a}}$ & $10 \pm 5$ & $1.37 \pm 0.10$ & $131.2 \pm 11.1$ & $95.8 \pm 11.2$ \\
\hline & 15 & UC & USU-420 & 29 & 95.7 & 94.1 & 1.02 & 0.08 & -0.16 & $11 \pm 4$ & $1.95 \pm 0.53^{b}$ & $101.9 \pm 6.9$ & $52.2 \pm 14.8$ \\
\hline & 18 & $\mathrm{RH}$ & USU-305 & 37 & 46.9 & 42.5 & 1.10 & 0.30 & $-0.97^{a}$ & $25 \pm 4$ & $1.17 \pm 0.36^{b}$ & $46.5 \pm 4.5$ & $39.6 \pm 12.8$ \\
\hline & 19 & $\mathrm{RH}$ & USU-306 & 26 & 21.5 & 21.8 & 0.98 & 0.19 & -0.72 & $20 \pm 5$ & $1.43 \pm 0.43^{b}$ & $22.3 \pm 2.4$ & $15.6 \pm 5.0$ \\
\hline & 20 & RH & USU-307 & 21 & 47.2 & 44.6 & 1.06 & 0.51 & -0.25 & $22 \pm 6$ & $1.07 \pm 0.29^{b}$ & $48.5 \pm 6.5$ & $45.4 \pm 13.9$ \\
\hline & 21 & $\mathrm{RH}$ & USU-648 & 23 & 25.9 & 24.7 & 1.05 & 0.01 & $-1.11^{\mathrm{a}}$ & $9 \pm 4$ & $1.55 \pm 0.21$ & $27.4 \pm 1.9$ & $17.7 \pm 2.8$ \\
\hline & 22 & $\mathrm{RH}$ & USU-649 & 22 & 28.2 & 27.1 & 1.04 & $0.92^{\mathrm{a}}$ & 0.37 & $17 \pm 4$ & $1.21 \pm 0.08$ & $28.08 \pm 2.6$ & $23.2 \pm 2.9$ \\
\hline & 22 & $\mathrm{RH}$ & USU-650 & 27 & 27.0 & 29.1 & 0.93 & -0.30 & $-1.29^{\mathrm{a}}$ & $19 \pm 4$ & $1.07 \pm 0.11$ & $26.7 \pm 2.4$ & $25.0 \pm 3.6$ \\
\hline & 24 & KC & USU-422 & 25 & 27.7 & 27.6 & 1.00 & 0.39 & $1.47^{\mathrm{a}}$ & $10 \pm 4$ & $2.07 \pm 0.57^{b}$ & $28.8 \pm 2.2$ & $13.9 \pm 4.0$ \\
\hline & 25 & $\mathrm{KC}$ & USU-655 & 27 & 29.2 & 29.6 & 0.99 & -0.29 & -0.59 & $33 \pm 6$ & $2.11 \pm 0.16$ & $27.8 \pm 4.1$ & $13.2 \pm 2.3$ \\
\hline & 26 & $\mathrm{KC}$ & USU-656 & 27 & 31.6 & 30.9 & 1.02 & 0.29 & -0.65 & $21 \pm 4$ & $1.51 \pm 0.10$ & $31.5 \pm 3.2$ & $20.8 \pm 2.7$ \\
\hline
\end{tabular}

a. significant kurtosis or skew following Arnold et al. (2007).

b. dose rate determined from the sand-sized fractions of excavated sheetllood deposits, see Table 1 for details. 
This is an author-produced, peer-reviewed version of this article. The final, definitive version of this document can be found online at Quaternary Geochronology, published by Elsevier. Copyright restrictions may apply. doi: 10.1016/j.quageo.2014.03.004

Table 3.

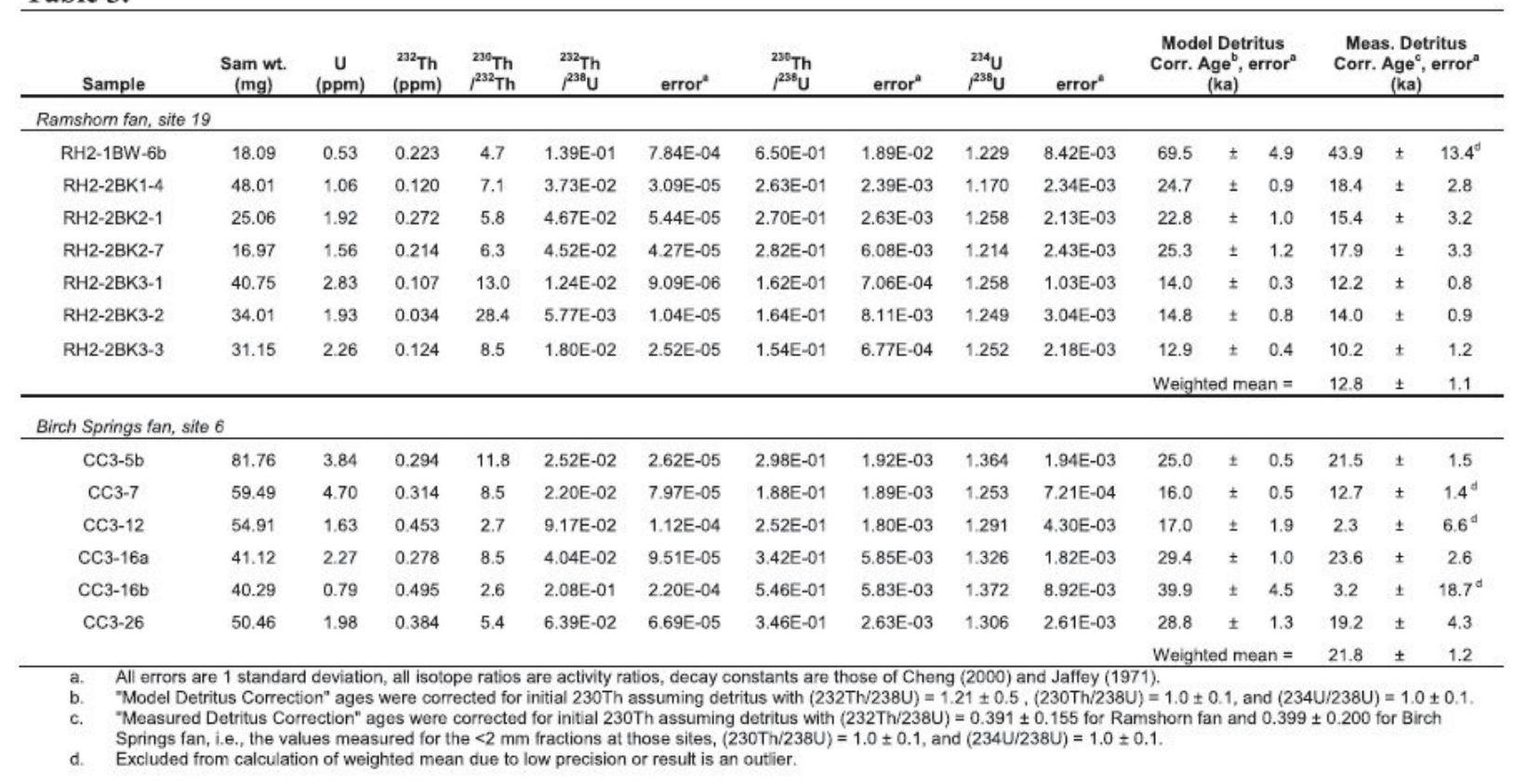

